\title{
Apparent body tilt and postural aftereffect
}

\author{
ATSUKI HIGASHIYAMA \\ Ritsumeikan University, Kyoto, Japan \\ and \\ KAZUO KOGA \\ Nagoya University, Nagoya, Japan
}

\begin{abstract}
Apparent orientation of the body tilted laterally in the frontal plane was studied with the methods of absolute judgments in four experiments. In Experiment 1, 17 subjects, who maintained the normal adaptation of body to gravity, estimated their body tilts under the condition of seeing the gravitational vertical and under the condition of eliminating it. The results showed that (1) there was not a significant difference between the two conditions and (2) the small tilts of less than $45^{\circ}$ were exactly estimated, whereas the large tilts of $45^{\circ}-108^{\circ}$ were overestimated. In Experiment 2,10 subjects estimated their body tilts under three velocities of a rotating chair on which each subject was placed. Although both body tilt and chair velocity were found to influence tilt estimation, the effect of body tilt was overwhelmingly greater than that of chair velocity. In Experiment 3, 11 subjects adapted their bodies to a $72^{\circ}$ left tilt for $10 \mathrm{~min}$ and then estimated various body tilts around the adapting tilt. The estimations obtained under the $72^{\circ}$ adaptation were lower than those obtained under the $0^{\circ}$ adaptation, and this reduction was greater for the test tilt that was farther away from the adapting tilt. In Experiment 4, 11 subjects adjusted their own body tilts to designated angles. The results confirmed the outcomes of absolute estimation in Experiments 1-3. From these findings and past literature, the judgments of body tilt were considered to be subserved by a single sensory process that was based on the cutaneous and muscular proprioceptors, rather than the vestibular and joint proprioceptors.
\end{abstract}

We investigated apparent orientation of the body by tilting it laterally in the frontal plane. ${ }^{1}$ The first concern was to establish psychophysical scale for body tilt under normal adaptation of the body to gravity. The second concern was to explore the processes and proprioceptors that make the perception of body tilt possible. For the latter concern, we made use of postural aftereffects or postural persistence: the sense of position of a limb, the head, or the eyes that may be temporarily affected when an asymmetrical posture is maintained for some time (F. J. Clark \& Horch, 1986; Howard, 1982). In this study, after being placed at a certain fixed tilt for some time, the subjects judged their various body tilts around the fixed tilt. On the basis of extent and magnitude of postural aftereffects, we assessed how many processes (single or double) exert in the perception of body tilt. Moreover, we considered how the processes are related to the nonvisual proprioceptors, such as the cutaneous, vestibular, joint, and muscular proprioceptors. ${ }^{2}$

One conventional method of measuring apparent body tilt is to have the subject indicate his or her apparent body

The authors are grateful to Y. Ohta, who helped collect the data of Experiments 2 and 3 , and to $\mathrm{K}$. Shimono, who critically read the earlier manuscript. Correspondence should be addressed to K. Koga, Research Institute of Environmental Medicine, Nagoya University, Furo-cho Nagoya 464-01, Japan (e-mail: koga@riem.nagoya-u.ac.jp), or to A. Higashiyama, Department of Psychology, Faculty of Letters, Ritsumeikan University, Kita-ku, Kyoto 603-77, Japan (e-mail: achan@ kic.ritsumei.ac.jp). tilt in space by aligning a visual rod (Asch \& Witkin, 1948a, 1948b; Bauermeister, 1964; Tschermak-Seysenegg, 1942/ 1952) or a nonvisual, haptic rod (Bauermeister, Werner, \& Wapner, 1964) to the reference. In this method, the reference to which the rod is adjusted is often the visual vertical (or horizontal) or the subject's body axis, and a difference in orientation between the adjusted rod and the reference is used as perceptual precision of the apparent vertical or apparent body tilt.

In this study, however, we did not use the method of aligning a visual rod to body orientation as a measure of apparent body tilt, because orientation of the visual rod interacts with postural orientation. Judgments of body tilts (Cohen \& Larson, 1974; Nemire \& Cohen, 1993; Sigman, Goodenough, \& Flannagan, 1979; Witkin, 1949), head tilts (Ebenholtz \& Benzschawel, 1977; Wade \& Day, 1968), and eye positions (Cohen, Ebenholtz, \& Linder, 1995; Matin \& Fox, 1989; Matin \& Li, 1994; Stoper \& Cohen, $1986,1989)$ vary with changes of visual environment.

Conversely, judgments of visual orientation vary with changes of postural orientation. Much evidence (e.g., Ebenholtz, 1977; Howard \& Templeton, 1966; Schöne \& Lechner-Steinleitner, 1978; Wade, 1968, 1970; Wade \& Day, 1968; Yardley, 1990) has indicated that when we tilt our head (or body) $45^{\circ}$ or more to one side in the frontal plane, a visual line that is parallel to gravity is perceived as tilting to the opposite direction of the head tilt (the A effect); whereas, with a head tilt of less than $45^{\circ}$, the visual line is perceived as tilting in the same direction as the head tilt (the E effect). When the head is slanted back- 
ward in the median plane, the gaze direction judged as straight ahead is higher than that obtained before backward slanting (Shebilske \& Fogelgren, 1977; Shebilske \& Karmiohl, 1978).

Another method of measuring apparent body tilt is to make verbal estimation of body tilt (Ebenholtz, 1970; Ebenholtz \& Shebilske, 1973; Fujita, 1956) or to place the body itself to a given reference (Cohen \& Larson, 1974; Nemire \& Cohen, 1993). One feature of this method is not to use an external tool, such as a rod, by which the subject indicates his or her own body tilt. Fujita (1956) found overestimation for $60^{\circ}-150^{\circ}$ left body tilts and exact estimation for $30^{\circ}$ and $180^{\circ}$ left body tilts. Ebenholtz (1970) obtained verbal estimations of apparent body orientation in the frontal plane and the median plane: For the frontal plane, the body tilt was increasingly overestimated as the body was tilted up to $30^{\circ}$, and then the overestimation was decreased; underestimation was finally obtained at $90^{\circ}$. For the median plane, the body slant was increasingly overestimated up to $90^{\circ}$. It was also demonstrated that the estimation for backward body slants of $0^{\circ}, 25^{\circ}$, and $75^{\circ}$ in the median plane was correct under the apparent instructions but was not correct under the objective instructions (Ebenholtz \& Shebilske, 1973). However, Cohen and Larson (1974) showed that when the body was aligned to the $15^{\circ}-60^{\circ}$ slants in the median plane, the adjusted body slants exceeded the references (i.e., underestimation of slants).

In this study, we used the methods of absolute estimation and absolute production by repairing drawbacks in previous studies. First, we attempted to control the adaptation level of body proprioception. To maintain the adaptation of the upright body to the gravity $\left(0^{\circ}\right)$, the body during the judgments of body tilt was alternately tilted to the left and right of the gravitational vertical; similarly, to maintain the adaptation of a certain fixed, tilted body to the gravity, the body was alternately tilted to the left and right of the particular tilt. This procedure was simple but necessary to control postural aftereffects. In previous studies where the body was tilted only to the left (Fujita, 1956), to the right (Ebenholtz, 1970), or backward (Ebenholtz \& Shebilske, 1973), asymmetrical postural aftereffects seem to have taken place, so that the judgments of body tilt may have differed from those under the $0^{\circ}$ adaptation (Pearson \& Hauty, 1959).

The second improvement was the balanced scaling procedure. The scale from magnitude estimation usually differs from that from magnitude production, and, hence, a true scale has been considered to be somewhere between the two scales (e.g., Gescheider, 1985). Therefore, a scale for body tilt was constructed with both methods of absolute estimation and absolute production. In Experiments $1-3$, the subjects verbally estimated their body tilts. Under the $0^{\circ}$ adaptation, the subjects were tilted at each of 15 positions between the $108^{\circ}$ left and the $108^{\circ}$ right tilt of the gravitational vertical; under the $72^{\circ}$ adaptation, the subjects were tilted at each of 11 positions between the $90^{\circ}$ left and the $90^{\circ}$ right tilt of the adapting tilt. In Experiment 4 , the subjects aligned their own bodies to each of the designated tilts. Under the $0^{\circ}$ adaptation, nine positions between the $120^{\circ}$ left and the $120^{\circ}$ right tilt of the gravitational vertical were designated to the subjects as the references; under the $72^{\circ}$ adaptation, nine positions between the $102^{\circ}$ left and the $102^{\circ}$ right tilt of the adapting tilts were designated as the references. These estimations and productions enabled us to scrutinize subtle trends of the judgments of body tilt. This may be in contrast with previous studies in which either estimations or productions were obtained for body tilts of less than $90^{\circ}$.

\section{GENERAL METHOD OF EXPERIMENTS 1-3}

\section{Apparatus}

The subject was placed in a chair on an apparatus capable of rotation to any angle in the frontal plane. The position of the chair was controlled by the analog voltage servo regulation system with accuracy of $1^{\circ}$. Figure 1 is a photograph of the apparatus and a subject who was tilted $30^{\circ}$ in the apparatus. The pivot on which the body rotated was located approximately at the midpoint between the eyes. A padded, adjustable iron structure was used to minimize shifts in the trunk, shoulder, wrist, and thigh. The head was also stabilized with the restraining structure, so that the subject could not shake, nod, or incline his or her head. To maintain verbal communication with the experimenter, the subject did not bite a board. The chair could be rotated into position either clockwise (CW) or counterclockwise $(\mathrm{CCW})$. We use the plus sign $(+)$ to signify $\mathrm{CW}$ from the gravitational vertical, and the minus sign (-) to signify $\mathrm{CCW}$ from the gravitational vertical. Figure 2 shows the three body tilts: the gravitational vertical, an $18^{\circ} \mathrm{CW}$ tilt, and a $108^{\circ} \mathrm{CCW}$ tilt.

The subjects faced a white hemisphere screen at a distance of about $180 \mathrm{~cm}$ from the midpoint of the eyes. The visual angle of the screen was $220^{\circ}$, and its luminance was 1.9 nit. Therefore, when the subjects fixated the center of the screen without eye movement, they saw the white screen only; when the subjects moved the eyes freely, they could see the knees as well as the screen. The midpoint of the eyes was at the center of the screen. Six red circles $(2 \mathrm{~cm}$ in diameter), with a center-to-center distance of $6.5 \mathrm{~cm}$, were drawn on the screen. The array of circles ran parallel to the gravitational vertical, and the top circle was positioned at the height of the head. The circles were definitely discerned in the dim laboratory.

\section{Procedure}

In Experiments 1-3, the subjects were asked to estimate their body tilts in degrees, relative to the gravitational vertical. The tilt angle of subject's body and the velocity of the rotating chair varied among experiments. In Experiment 1,15 positions between $-108^{\circ}$ and $108^{\circ}$ tilts were used under a rotation velocity of $1.12 \mathrm{rpm}$. In Experiment 2, the same positions as those in Experiment 1 were used under rotation velocities of $0.41,0.79$, and $1.07 \mathrm{rpm}$. In Experiment 3,11 positions between $-18^{\circ}$ and $162^{\circ}$ tilts were used under a rotation velocity of $1.12 \mathrm{rpm}$. In each experiment, the chair was alternately rotated $\mathrm{CW}$ and $\mathrm{CCW}$ and was stopped at each position. There were no training trials in any experiment; each position was estimated three or four times.

The main part of the instructions to the subjects in Experiments 1-3 were as follows:

I am going to tilt your chair in different orientations. Your task in each orientation is to estimate how large the tilt appears by reporting numbers 


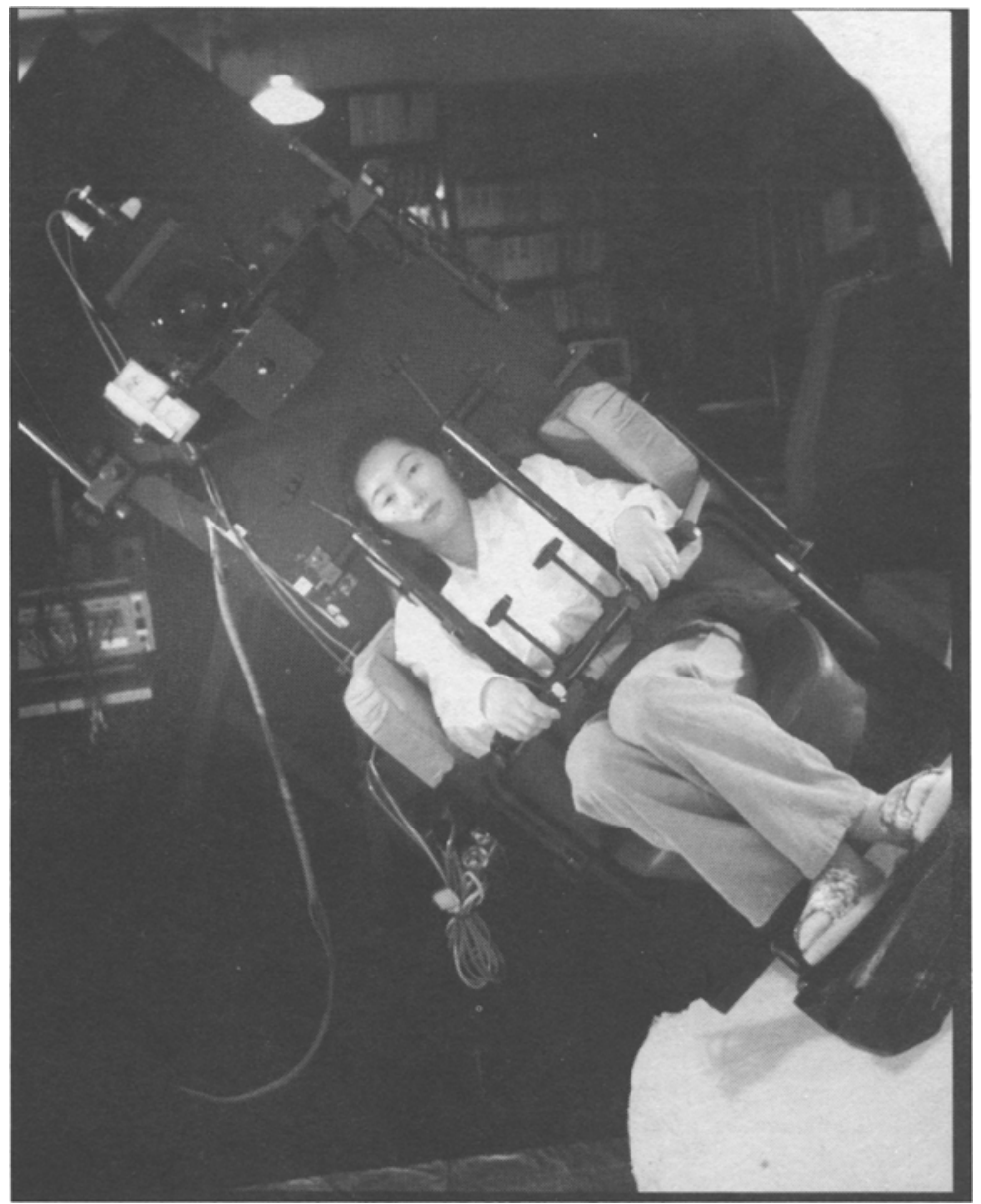

Figure 1. A photograph of the apparatus and a subject seated in the rotating chair.

in degrees. You should designate the gravitational upright $0^{\circ}$ and designate the horizontal orientation $90^{\circ}$. In making estimation of body tilt, I would like to suggest that you imagine that your body were the hour hand on a large clock. For example, if the body is supposed to indicate 10 'clock, then the orientation should be designated $30^{\circ}$; if the body is supposed to indicate 20 'clock, then the orientation should be designated $60^{\circ}$. Please use any number you may consider appropriate; you should not think that the numbers to be used are limited to 30 and its multiples.

In these instructions, the subjects were not told that the center of rotation was at the midpoint between the eyes. Each subject indeed perceived the body to be tilted by rotation of the chair but did not realize the center of rotation. Nevertheless, all subjects in this study correctly understood what was intended by the instructions. Theoretically, it is not important to know the center of rotation in tilt judgments, because the body tilt should be judged relative to the gravitational vertical.

After completing the estimation of body tilt, the subjects estimated visually presented plane angles in degrees, each of which was formed by drawing two line segments $(4 \mathrm{~cm}$ long $\times 0.4 \mathrm{~mm}$ wide) in wedge on a white card $(10 \mathrm{~cm}$ high $\times 10 \mathrm{~cm}$ wide $)$. One line was the gravitational vertical, and the other was tilted from the gravitational vertical. The angles between the vertical line and the tilted line were the same as the angles used in estimation of body tilt in each experiment. The instructions used in the plane angle estimation were similar to those used in the body tilt estimation. The trials for plane angle were composed of three blocks, each block containing different plane angles. There were no training trials. Each angle was binocularly observed in the frontal plane at a distance of about $50 \mathrm{~cm}$.

\section{EXPERIMENT 1}

In Experiment 1, to provide baseline measures of body tilt, we obtained absolute estimations of body tilt under the normal $0^{\circ}$ adaptation. By the $0^{\circ}$ adaptation, we mean a proprioceptive adaptation to the condition where the body axis coincides with the gravitational vertical. Note that we are usually in the $0^{\circ}$ adaptation. When we are waking and active, the body axis moves around and deviates to the left and right of the gravitational vertical, but the average body axis over time is assumed to coincide with the gravitational vertical.

We also explored how a visual cue indicating the gravitational vertical affected apparent body tilt. The estimations of body tilt were compared between the exposed condition where the gravitational vertical was visually indicated and the occluded condition where all visual cues to orientation were eliminated. 


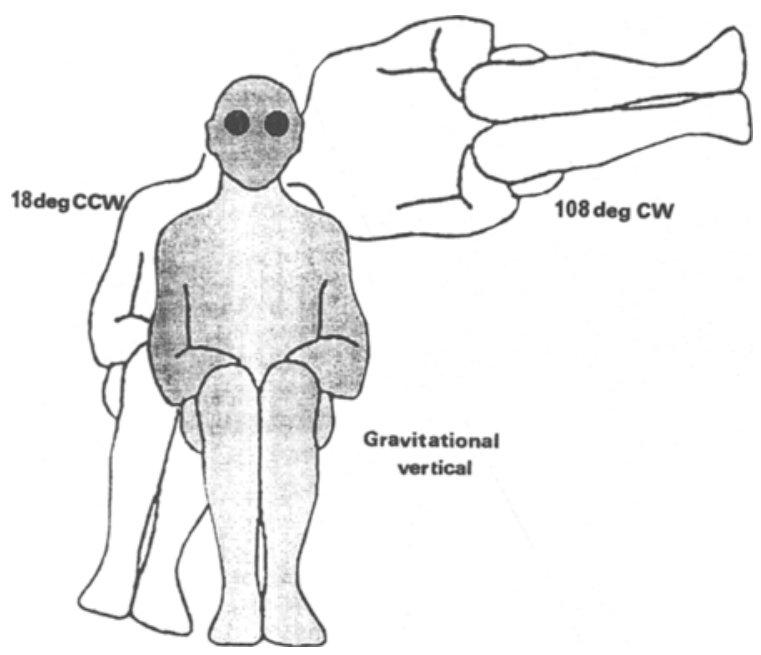

Figure 2. A schematic drawing of the subject in the three typical body tilts: the gravitational vertical, an $18^{\circ}$ clockwise $(\mathrm{CW})$ tilt, and a $108^{\circ}$ counterclockwise $(\mathrm{CCW})$ tilt.

\section{Method}

Subjects. The subjects were 17 ( 8 males and 9 females) paid undergraduates; none of them had any known deficits in visual acuity, motor, or vestibular functions.

Procedure. The tilts to be estimated were $0^{\circ}, \pm 9^{\circ}, \pm 18^{\circ}, \pm 36^{\circ}$, $\pm 54^{\circ}, \pm 72^{\circ}, \pm 90^{\circ}$, and $\pm 108^{\circ}$. In a given trial, the chair was rotated and was stopped at the preset position. The subject was then required to estimate the body tilt quickly. After obtaining an estimation for the tilt, we again rotated the chair to the next preset position. Whenever the chair was rotated for the next trial, it traversed the upright position; it was not upside down at any time.

There were two visual conditions. In the exposed condition, we provided the subject with the circles arranged along the gravitational vertical on the screen and reminded him or her that the array of circles should be used as a reference in estimating body tilt. In the occluded condition, the subject's eyes were covered with a blindfold to eliminate all visual cues.

The trials were composed of six blocks, each block containing the 15 different tilts. Eight of the subjects estimated body tilts with occluded eyes in the first three blocks and with open eyes in the following three blocks. The remaining 9 subjects judged in the reverse order. Thus, each subject provided 90 ( 2 conditions $\times 3$ blocks $\times$ 15 trials) estimations. The order of trials in each block was randomly determined, with the restriction that the trials were composed of an alternation of left and right body tilts of the gravitational vertical (e.g., $-9^{\circ},+54^{\circ},-90^{\circ},+0^{\circ}$, etc.).

After completing the estimation of body tilt, the subjects estimated the 14 visually presented plane angles, which lay in the range of $-108^{\circ}$ to $+108^{\circ}$. These plane angles were the same magnitudes as those used in body tilt estimation (except that the plane angle $0^{\circ}$ was not used).

\section{Results and Discussion}

Mean estimation. Figure 3 shows the results. The ordinate $(y)$ represents the mean tilt of 51 estimations ( 3 trials $\times 17$ subjects) and the abscissa $(x)$ represents the objective body tilt, with positive for the CW tilts and negative for the $\mathrm{CCW}$ tilts. The parameter is the block condition (left) and the visual condition (right). The main effect of tilt was significant $[F(14,28)=798.8, p<$ $.001]$, and the interaction of tilt with block was significant $[F(28,448)=4.01, p<.01]$. The main effect of condition (open vs. occluded) was not significant, and the interaction of condition with any other source was not significant.

For simplicity, we fitted a least squares line to the mean tilts in each block and obtained the slope, intercept, coefficient of determination $\left(r^{2}\right)$, and $95 \%$ confidence interval (CI) around the slope. Table 1 shows the results.
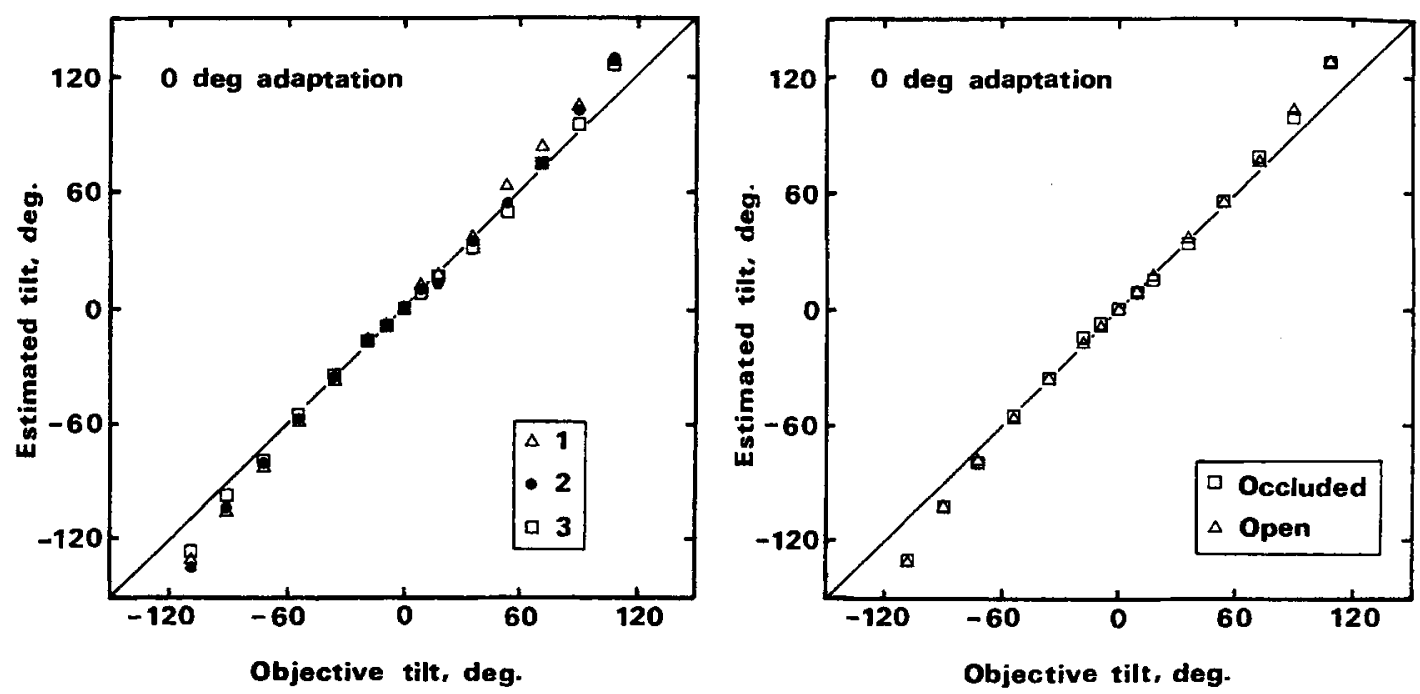

Figure 3. Mean absolute estimation (in degrees) as a function of body tilt (in degrees). The parameter is the block (left) and the visual condition (right). The diagonal line in each panel represents the perfect estimation. 
Table 1

Slope, Intercept, Coefficient of Determination $\left(r^{2}\right)$, and $95 \%$ Confidence Interval (CI) Around the Slope of the Linear Function Fitted to the Mean Estimations in Each Block Under the $0^{\circ}$ Adaptation

\begin{tabular}{ccccc}
\hline Block & Slope & Intercept & $r^{2}$ & CI \\
\hline 1 & 1.17 & 0.27 & .999 & $1.14-1.19$ \\
2 & 1.14 & -0.68 & .994 & $1.08-1.19$ \\
3 & 1.09 & -0.87 & .995 & $1.04-1.13$ \\
\hline
\end{tabular}

Clearly, the obtained slope decreased as the block progressed, and it was significantly larger than unity even at the final third block.

We again fitted a least squares line to each of the three tilt ranges (i.e., $-108^{\circ}$ to $-54^{\circ},-36^{\circ}$ to $36^{\circ}$, and $54^{\circ}$ to $108^{\circ}$ ) in each block, because an inspection of Figure 3 appeared to reveal a shallow slope for small tilts and a steep slope for large tilts. Table 2 shows the results. The mean line taken over blocks was $y=0.97 x-0.18$ for the small tilts and was $y=1.35 x \pm 17.8$ for the large tilts (where the positive and negative intercepts were for the $\mathrm{CCW}$ and CW tilts, respectively). This suggests that the small tilts were exactly estimated and the large tilts were overestimated. The overestimation was more amplified for larger tilts (e.g., $5 \%$ for $60^{\circ}, 13 \%$ for $80^{\circ}$, and $17 \%$ for $100^{\circ}$ ).

Figure $4 \mathrm{~A}$ shows the mean estimations ( 3 trials $\times 17$ subjects) of visually presented plane angle against objective plane angle. The best-fitting least squares function was $y=1.01 x-0.01\left(r^{2}=1.00\right)$, with the $95 \% \mathrm{CI}$ around the slope being 1.00-1.02. Thus, the mean estimations of plane angle were precise over the entire range of stimuli, in contrast to the estimations of body tilt.

The mean estimations in the occluded condition were not different from those in the exposed condition. This result suggests that the estimations for apparent body tilt were determined by nonvisual information that was provided through the cutaneous, vestibular, joint, and/or muscular proprioceptors. This result supports those found by Miller and Hall (1963), Stoffregen and Riccio (1988), and Nemire and Cohen (1993), who acknowledged the importance of visual information in the perception of body tilt but, at the same time, considered the nonvisual information as primacy.

We should not be surprised at the finding that the visual cue indicating the gravitational vertical did not have any effect on estimation of body tilt. Previous studies
(Ebenholtz \& Benzschawel, 1977; Howard, 1982; Howard \& Templeton, 1966; Mann, 1952; Nemire \& Cohen, 1993; Passey, 1950; Sigman et al., 1979; Witkin, 1949) have indicated that a tilted visual frame leads to errors in postural orientation and that the upright body or head is perceived to be tilted in the opposite direction of the frame tilt. This may imply that an upright visual frame does not have effects on postural orientation. For example, Passey (1950) required the subject in an upright or tilted room to adjust his body to the upright position from a laterally tilted position and found that the mean constant error from the gravitational vertical was $0.35^{\circ}$ for the upright room and was $1.4^{\circ}$ even for the $20^{\circ}$ tilting room. It thus seems that (1) for the upright visual frame, the postural vertical approximately agreed with the gravitational vertical, and (2) for the tilted visual frame, the postural vertical was greatly biased by the frame in some studies (e.g., Witkin, 1949) but was less in other studies (e.g., Mann, 1952; Passey, 1950).

One could interpret ineffectiveness of the visual cue in this experiment by the poor visual structure in this experiment (i.e., six vertically arranged circles on homogeneous screen). However, there is evidence against this interpretation. Nemire and Cohen (1993) examined the effects of visual structure around the subject (grid pattern, parallel lines, and darkness) on adjustment of body slant. They found that, under the upright visual frame, there was no difference in adjustments of body slant among the visual-structure conditions, whereas under the tilted visual frame, the grid pattern was the most effective and the parallel lines were more effective than the darkness. It is thus suggested that visual structure is effective only for the tilted visual frame.

As the block progressed, the slope of the best-fitting linear function decreased and approached unity (i.e., precise estimation). This result parallels the studies of Solley (1956) and Pearson and Hauty (1959), who showed that when the subjects were asked to return themselves from a laterally tilted position to the apparent vertical, the difference between the adjusted tilt and the true vertical was reduced over a series of trials, even though the subjects were not told either the magnitude or the direction of their errors.

It is difficult to assume that incorrect estimation for the large body tilts was due to bias of the verbal system. As is shown in Figure 4A, the subjects were capable of

Table 2

Slope, Intercept, and Coefficient of Determination $\left(r^{2}\right)$ of the Linear Functions Fitted to the Mean Estimations for Each of the Three Ranges $\left(x<-54^{\circ},-36^{\circ}<x<36^{\circ}\right.$, and $\left.x>54^{\circ}\right)$ as a Function of Block Under the $0^{\circ}$ Adaptation

\begin{tabular}{|c|c|c|c|c|c|c|c|c|c|}
\hline \multirow[b]{2}{*}{ Block } & \multicolumn{3}{|c|}{ Small } & \multicolumn{3}{|c|}{ Large $(\mathrm{CCW})$} & \multicolumn{3}{|c|}{ Large $(\mathrm{CW})$} \\
\hline & Slope & Intercept & $r^{2}$ & Slope & Intercept & $r^{2}$ & Slope & Intercept & $r^{2}$ \\
\hline 1 & 1.04 & & .998 & & & & & & .9 \\
\hline 2 & & & & & & & & & .99 \\
\hline 3 & 0.92 & & .999 & & & .994 & 1.38 & & .994 \\
\hline Overall & 0.97 & -0.18 & .998 & 1.36 & 18.61 & .997 & 1.33 & -16.96 & .997 \\
\hline
\end{tabular}



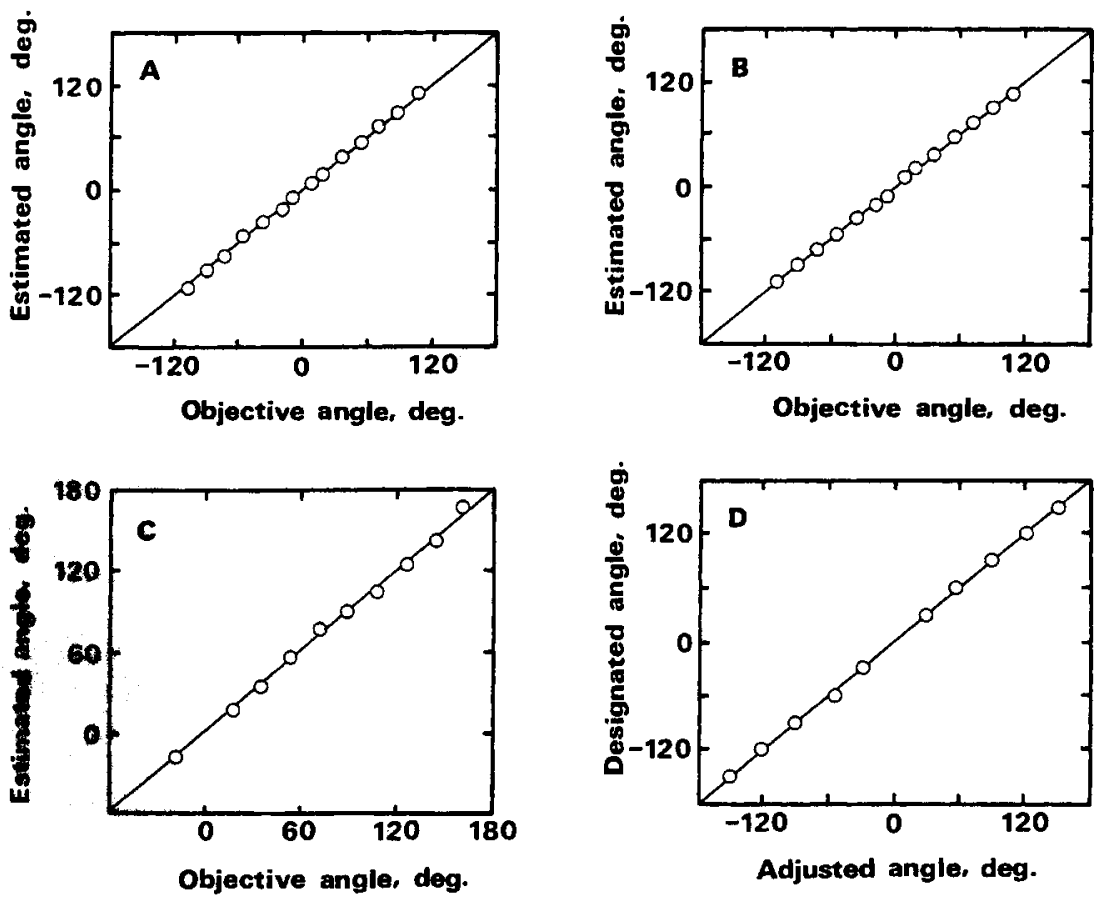

Figure 4. Mean absolute estimation and production for angle of two intersecting visual sogments in the frontal plane. In Panels $A, B$, and $C$, the mean estimation (in degrees) is shown against visually presented plane angle (in degrees) in Experiments 1, 2, and 3, respectively. In Panel D, the designated angle (in degrees) is shown against mean production angle (in degrees) in Experiment 4.

assigning numbers in proportion to visual plane angle. Because the verbal system was used in both tasks of estimating body tilt and plane angle, the incorrect estimations of body tilt have to be ascribed to a system other than the verbal system-probably to a sensory system.

Variability of extimation. The estimation data were also analyzed in terms of the between- and the withinsubjects variability. The between-subjects variability was defined as a standard deviation of the individual mean estimations, each of which was based on the three estimations. The within-subjects variability was defined as a mean of the individual standard deviations. Figure 5 shows the between-subjects (left) and the within-subjects (right) variabilities as a function of body tilt (or plane angle). The parameter was the estimation task.

Although the between-subjects variability was about twice as large as the within-subjects variability, the features of the two variabilities seemed to be very similar to one another. First, the variability of estimation for body tilt was larger than that for visual plane angle. This implies that discrimination of body tilt was coarser than that of plane angle.

Second, the estimation of body tilt in the occluded condition was much more variable than that in the exposed condition. This may support the suggestion of Nemire and Cohen (1993): When the subjects were placed on a foam cushion that reduced cutaneous input from the foot, addition of visual cues about the direction of grav- ity reduced the between-subjects variability of slant judgments, whereas when the subjects were placed on a rigid surface of support that provided them ample cutaneous input, adding the visual cues did not decrease the variability. In our experiment, the rotating chair may have been functionally equivalent to the foam cushion.

Third, there was remarkable anisotropy of space: The variability of estimation was the least for the gravitational vertical, and it increased up to the body tilt of $60^{\circ}$ but reduced for the tilt of $60^{\circ}-90^{\circ}$ and again increased for the tilt of more than $90^{\circ}$. This result resembles the variability of visual vertical judgments obtained as a function of head and trunk position (Schöne \& Udo de Haes, 1968). This finding also supports the study of Dick and Hochstein (1989), who had the subjects estimate the absolute orientation of single visual lines and showed that the amount of information transmitted, which measures the degree of correlation between stimulus set and response set, was larger around the horizontal and vertical axes rather than the diagonal. Our finding demonstrated a strong anisotropy in body orientation as well as visual orientation.

\section{EXPERIMENT 2}

One could argue that the results of Experiment 1 are interpretable in terms of time to travel from the gravitational vertical to the goal tilt where the subjects estimated 

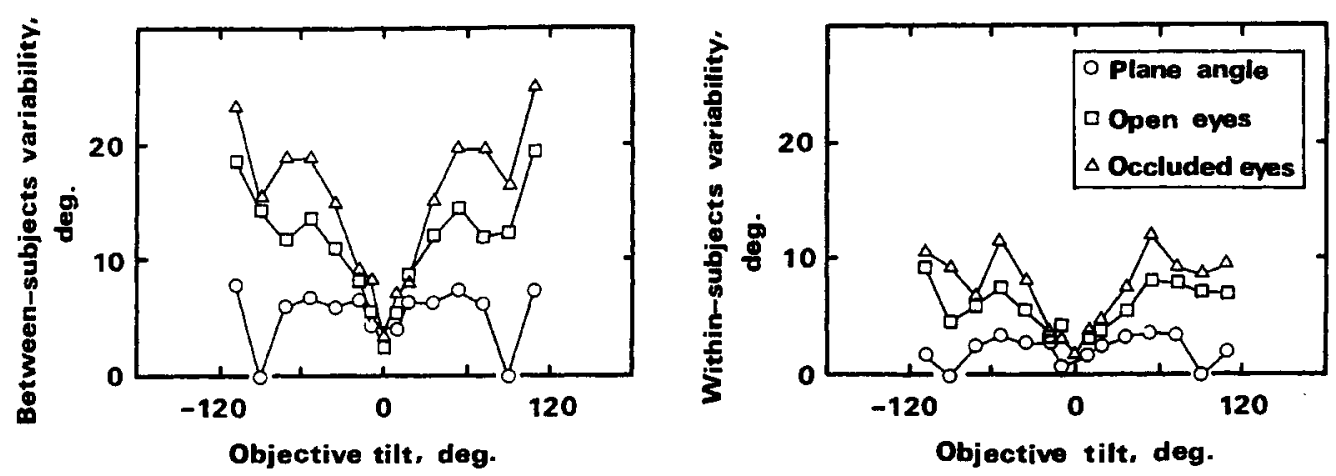

Figure 5. Between-subjects (left) and within-subjects (right) variability of estimation as a function of objective body tilt (or plane angle). The parameter is the viewing conditions in Experiment 1.

their body tilt. Since, in Experiment 1, we used only one velocity of the rotating chair $(1.12 \mathrm{rpm})$, it took longer to reach larger body tilt. Accordingly, it would be probable that the overestimation of body tilt was associated with longer travel time to the goal tilt. To examine this interpretation, the subjects in Experiment 2 estimated their body tilts under three rotation velocities. Since body tilt, rotation velocity, and travel time were interdependent in this situation, we attempted to find the genuine variable that affected the estimations of body tilt, by using an analysis of partial correlation and an analysis of multiple regression.

\section{Method}

Subjects. The subjects were 10 ( 5 males and 5 females) paid undergraduates; none of them had any known deficits in motor or vestibular functions.

Procedure. The subject was seated, blindfolded, in the rotating chair and did not take off the blindfold throughout the experiment. The body tilts to be estimated were the same as those used in Experiment 1 . The velocities of the rotating chair were $0.41,0.79$, and $1.07 \mathrm{rpm}$. The trials were composed of three blocks, each block containing the different tilts under a given rotation velocity. Thus, each subject provided 45 estimations ( 15 angles $\times 3$ velocities). The order of body tilts within each block was randomized for each subject, but, in the same way as in Experiment 1, it was balanced to be on either side of the gravitational vertical. The orders of velocities were counterbalanced among the subjects.

After completing the estimation of body tilt, the subjects estimated the 14 visually presented plane angles, which lay in the range of $-108^{\circ}$ to $+108^{\circ}$. These plane angles were the same as those used in Experiment 1.

\section{Results and Discussion}

In Experiment 2 and in the subsequent experiments, we present the mean estimations taken over the subjects, however, we do not present the between- and the withinsubjects variability of estimations, because these variabilities were similar to those in Figure 5 .

Figure 6 shows the mean estimations against objective body tilt, with velocity as the parameter. The main effect of tilt was significant $[F(14,126)=143.80, p<.001]$, and the interaction of tilt with velocity was significant $[F(28,252)=1.65, p<.05]$.

For each velocity, we fitted a least squares line to the mean tilts as a function of body tilt and obtained the slope, intercept, coefficient of determination $\left(r^{2}\right)$, and $95 \% \mathrm{CI}$ around the slope. Table 3 shows the results. Clearly, the slope decreased as the velocity increased, implying that the overestimation of body tilt was remarkable for slow velocity of the rotating chair.

Table 4 shows the simple and partial correlations between the mean estimation $(E)$ and the stimulus variables of tilt angle $(A)$ in degrees, rotation velocity $(V)$ in rpm, and travel time $(T)$ in seconds. (Note that $T$ was obtained by $A / V / 6$.) All correlations between $E$ and $A$ were significant, and all correlations between $E$ and $V$ were not sig-

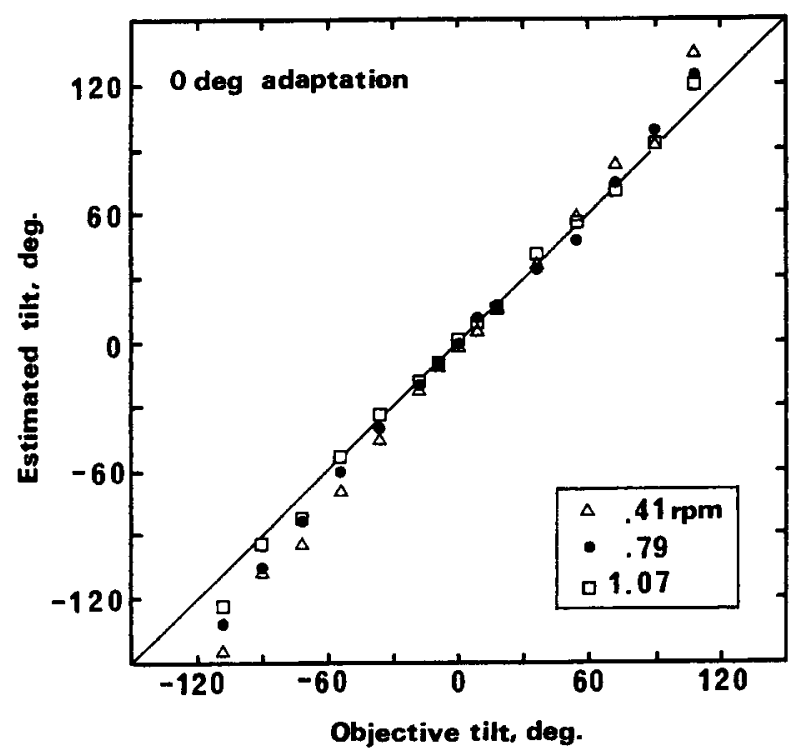

Figure 6. Mean absolute estimation (in degrees) against objective body tilt (in degrees). The parameter is the rotation per minute (rpm). The diagonal line represents the perfect estimation. 
Table 3

Slope, Intercept, Coefficient of Determination $\left(r^{2}\right)$, and $95 \%$ Confidence Interval (CI) Around the Slope of the Linear Function Fitted to the Mean Estimations for Each Velocity Under the $0^{\circ}$ Adaptation

\begin{tabular}{ccccc}
\hline Velocity (rpm) & Slope & Intercept & $r^{2}$ & CI \\
\hline .41 & 1.21 & -5.25 & .995 & $1.16-1.26$ \\
.79 & 1.12 & -3.30 & .998 & $1.08-1.17$ \\
1.07 & 1.07 & -0.85 & .998 & $1.03-1.11$ \\
\hline
\end{tabular}

nificant. This means that $A$ strongly affected estimation of body tilt, but rotation velocity did not. The effect of $T$ on estimation of body tilt was moderate: $r(E, T)$ and $r(E$, $T ; V$ ) were more than .93 , but when the effect of tilt angle was eliminated, the influence of $T$ on estimation of body tilt was greatly lowered [i.e., $r(E, T ; A)=.454$, and $r(E$, $T ; A, V)=.459]$.

We also applied an analysis of multiple regression to the same estimation data in Experiment 2 . The $\beta$ coefficients of $A(.917, p<.001)$ and $T(.087, p<.01)$ were significant, but the $\beta$ coefficient of $V(.012)$ was not. A comparison of $\beta$ coefficients between $A$ and $T$ suggests that $A$, rather than $T$, overwhelmingly affected the estimation of body tilt.

Figure 4B shows the mean estimations ( 3 trials $\times 10$ subjects) of visually presented plane angle against objective angle. The best-fitting least squares function was $y=1.00 x+0.03\left(r^{2}=.999\right)$, with the $95 \% \mathrm{CI}$ around the slope being $0.98-1.02$. Thus, the estimations of plane angle were precise over all stimuli.

\section{EXPERIMENT 3}

The baseline measures obtained in Experiments 1 and 2 are characterized as exact estimation of small tilts and overestimation of large tilts. One possible explanation of this result is to assume two independent processes that make selective responses to body tilt: One is sensitive to small tilts, and the other is responsive to large tilts. Evidence for the two-process model may be provided by the idea that (1) the E effect is likely to take place for small body tilts, whereas the A effect is for large body tilts, and (2) the effects of the otolith organs, which are sensitive to the shear force of gravity, are very sensitive to small tilts around the gravitational vertical, but not stable for the large tilt of $90^{\circ}$ or more (Graybiel \& Patterson, 1955; Quix, 1925; Schöne, 1964; Schöne \& Mortag, 1968; Schöne \& Wade, 1971; Udo de Haes, 1970). It is also possible to assume that a single process exerted over all tilts. In this case, the difference in slope between the small and the large tilts should not be considered evidence for the twoprocess model, but rather it should be interpreted as an operating characteristic of the single process.

In Experiment 3, by investigating postural aftereffects, we attempted to understand the process underlying the perception of body tilt. For this purpose, the subject was first tilted by $72^{\circ}$ for $10 \mathrm{~min}$ (adapting tilt), and, follow- ing that, he or she estimated various body tilts around the adapting tilt.

It is possible to predict how the estimations of body tilt change by postural adaptation. First, since prolonged exposure to a fixed stimulus generally results in a decrease of sensitivity or apparent magnitude, the estimation of body tilt after adaptation may be smaller than the estimation before adaptation. Second, estimations of body tilt may be affected by the number of independent sensory processes. If the two-process model were correct, then the adaptation effect would be confined to large tilts in this experiment; if the single-process model is correct, then the adaptation effect extends not only to large tilts but to small tilts.

To predict relative magnitude of the adaptation effect, we have to consider two types of perceptual adaptations. First, an adaptation effect would be greatest for the adapting stimulus itself and would be less for the test stimulus that was more distant from the adapting stimulus. This type of adaptation should be called the on-adaptation, which has typically been found in chromatic adaptation. If we are continually exposed to the long-wavelength light that is usually seen as red, the sensitivity to the light is greatly reduced, but the sensitivity to the short-wavelength light seen as blue light is not affected (or little affected) by the prolonged exposure to the long-wavelength light. The onadaptation also takes place for the contrast sensitivity function. If we are continually exposed to a grating of 7.1 cycles per degree (cpd), the sensitivity to spatial frequency is dramatically reduced in the region of $7.1 \mathrm{cpd}$; however, such an adaptation effect has not been practically found beyond the frequencies of 2.5 and $11.9 \mathrm{cpd}$ (Blakemore \& Campbell, 1969).

Second, an adaptation effect would be greatest for the test stimulus that is, to some degree, far from the adapting stimulus and would be weak for the same test stimulus as the adapting stimulus. This type of adaptation should be called the off-adaptation, which has typically been known

Table 4

Simple and Partial Correlations Between the Mean Estimation $(E)$ and the Three Stimuli: Tilt Angle $(A)$, Rotation Velocity $(V)$, and Travel Time $(T)$

\begin{tabular}{lc}
\hline Condition* $^{*}$ & Correlation \\
\hline$r(E, A)$ & $.997 \ddagger$ \\
$r(E, T)$ & $.931 \ddagger$ \\
$r(E, V)$ & .012 \\
$r(E, A ; T)$ & $.983 \ddagger$ \\
$r(E, A ; V)$ & $.997 \ddagger$ \\
$r(E, T ; A)$ & $.454 \dagger$ \\
$r(E, T ; V)$ & $.932 \ddagger$ \\
$r(E, V ; A)$ & .154 \\
$r(E, V ; T)$ & .032 \\
$r(E, A ; T, V)$ & $.984 \ddagger$ \\
$r(E, T ; A, V)$ & $.459 \dagger$ \\
$r(E, V ; A, T)$ & .174 \\
\hline
\end{tabular}

${ }^{*} r(a, b)$ signifies a simple correlation between $a$ and $b ; r(a, b ; c)$ signifies a partial correlation between $a$ and $b$ when the effect of $c$ was eliminated; $r(a, b ; c, d)$ signifies a partial correlation between $a$ and $b$ when the effects of $c$ and $d$ were eliminated. $\quad{ }^{\dagger} p<.01 . \quad{ }^{\dagger} p<.001$. 
as distance paradox in figural aftereffects (e.g., Köhler \& Wallach, 1944; Robinson, 1972). For example, if a line, called the inspection figure, is fixated for a time, and then the other line, called the test figure, is placed in the visual field close to the position occupied by the fixated line, then the test figure is displaced away from the position of the inspection line. Interestingly, the maximum displacement of the test figure does not occur when the inspection and test figures coincide but when they are a short distance away from each other.

If the on-adaptation occurred in the perception of body tilt, its effect would be greatest for the adapting tilt itself and would be less for the test stimulus that was more distant from the adapting tilt. Figure $7 \mathrm{~A}$ shows a prediction for the on-adaptation, where apparent body tilt during and after the prolonged exposure to the $72^{\circ}$ body tilt is smaller than the baseline function for the $0^{\circ}$ adaptation. For the single-process model, the adaptation effect extends over the entire body tilts, with the greatest effect at the same test tilt as the adapting tilt. For the two-process model, the adaptation effect is limited to the large tilts and is less for the test stimulus that is more distant from the adapting stimuli.

The predictions for the off-adaptation are shown in Figure 7B. For the single-process model, the decrease of apparent body tilt due to adaptation is greater for the test stimulus that is farther away from the adapting stimulus and is smallest for the adapting stimulus itself. For the two-process model, the decrease of apparent body tilt is limited to the large tilts and is more remarkable for the test stimulus that is more distant from the adapting stimulus.

\section{Method}

Subjects. The subjects were 11 ( 3 males and 8 females) paid undergraduates and institute staff; none of them had any known deficits in motor or vestibular functions.

Procedure. The subject was seated, blindfolded, in the rotating chair used in Experiments 1 and 2. After the body was tilted by $72^{\circ}$ $\mathrm{CW}$ for $10 \mathrm{~min}$, the subject estimated the 11 body tilts that were at increments of $18^{\circ}$, to either side of the adapting tilt: $-18^{\circ}[72-(5 \times$ $18)], 0^{\circ}[72-(4 \times 18)],+18^{\circ}[72-(3 \times 18)],+36^{\circ}[72-$ $(2 \times 18)],+54^{\circ}(72-18),+72^{\circ},+90^{\circ}(72+18),+108^{\circ}[72+(2$ $\times 18)],+126^{\circ}[72+(3 \times 18)],+144^{\circ}[72+(4 \times 18)]$, and $+162^{\circ}$ $[72+(5 \times 18)]$. The trials were composed of three blocks, each block containing the 11 different tilts. Thus, each subject provided 33 ( 3 blocks $\times 11$ tilts) estimations. The order of trials in each block was randomly determined, under the restriction that the trials were composed of an alternation of a $72^{\circ}$ tilt or less and a $72^{\circ}$ tilt or more (e.g., $-18^{\circ},+90^{\circ},+72^{\circ},+162^{\circ}$, etc.). Whenever body tilt was changed for the next trial, the chair in which the subject was placed crossed over the adapting tilt to the next test position.

After completing the estimation of body tilt, the subjects estimated the 10 visually presented plane angles, which lay in the range of $-18^{\circ}$ to $+162^{\circ}$. These plane angles were the same magnitudes as those used in body tilt estimation (except that the plane angle $0^{\circ}$ was not used).

\section{Results and Discussion}

Figure 8 shows the mean estimations against body tilt, with block as the parameter. The main effect of tilt was significant $[F(10,100)=502.6, p<.001]$, and the interaction of tilt with block was significant $[F(20,200)=$ $2.94, p<.01]$.

We fitted a least squares line to the mean estimations in each block. The slope, intercept, coefficient of determination $\left(r^{2}\right)$, and $95 \% \mathrm{CI}$ around the slope are shown in Table 5. Clearly, the slope decreased as the block pro-
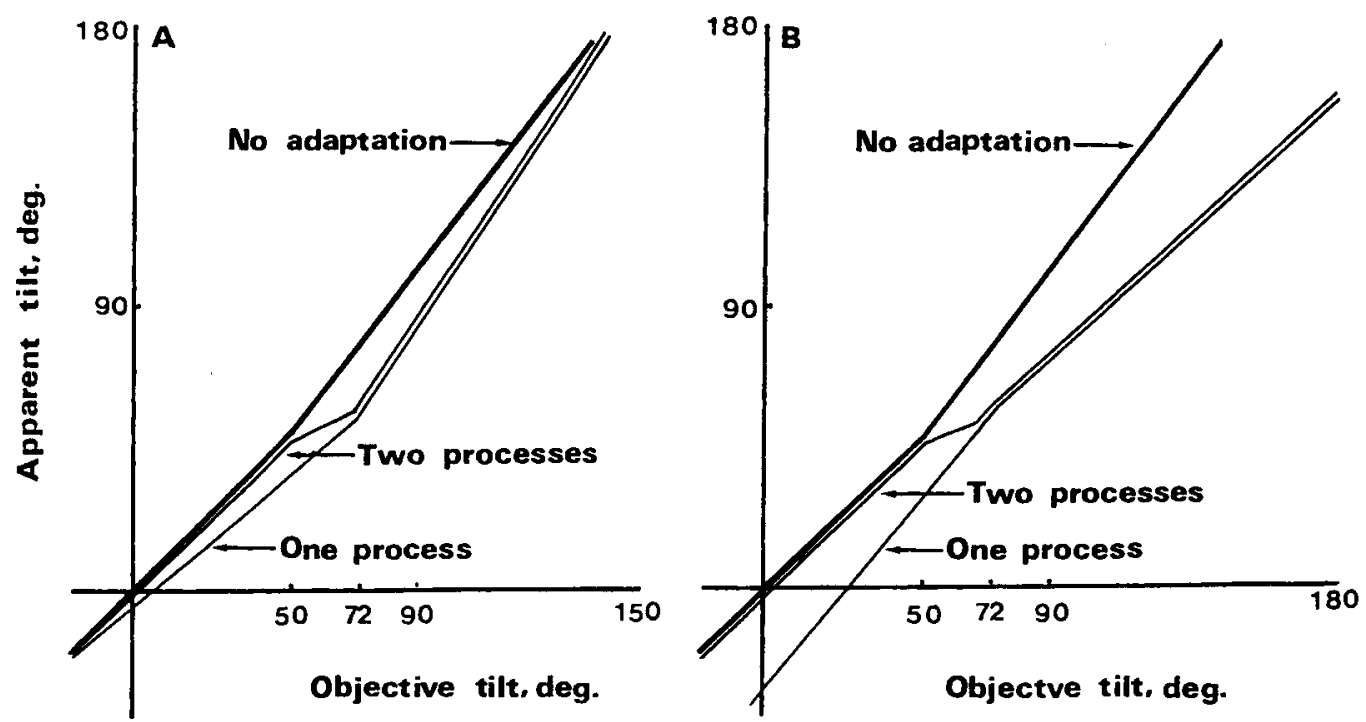

Figure 7. Prediction of apparent body tilt during prolonged exposure to a $72^{\circ}$ body tilt. The left panel represents the predictions based on the on-adaptation, and the right panel represents the predictions based on the offadaptation. See text for definitions of the on- and off-adaptations. In either adaptation, the thick line represents the function obtained under the $0^{\circ}$ adaptation (Experiment 1), and the thin line represents a prediction based on the one- or two-process model. 


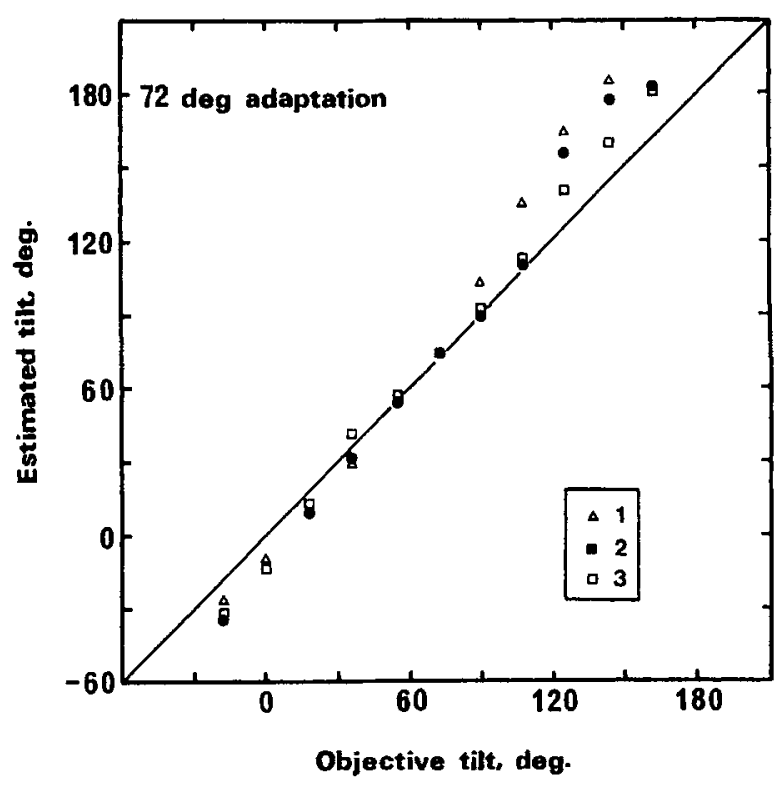

Figure 8. Mean absolute estimation (in degrees) against body tilt (in degrees). The parameter is the block. The diagonal line represents the perfect estimation.

gressed, and it was significantly larger than unity even at the final block.

To compare the results of Experiment 3 with the results of Experiment 1 (Table 2), the least squares lines were fitted separately to small tilts $\left(-18^{\circ}\right.$ to $\left.36^{\circ}\right)$ and large tilts $\left(54^{\circ}\right.$ to $\left.162^{\circ}\right)$. Table 6 shows the results: The mean function was $y=1.21 x-10.60$ for the small tilts, and $y=1.26 x-15.13$ for the large tilts.

Figure 9 helps us to compare the mean estimations for the $0^{\circ}$ adaptation in Experiment 1 with those for the $72^{\circ}$ adaptation in Experiment 3. Clearly, the mean estimations under the $72^{\circ}$ adaptation were generally smaller than those under the $0^{\circ}$ adaptation, and the reduction of estimation in the $72^{\circ}$ adaptation was greater for the stimuli that were farther away from the adapting tilt (i.e., the offadaptation). In addition, the adaptation effect extended not only to the large tilts but to the small tilts. This provides evidence for the single-process model.

The results for visually presented plane angle are shown in Figure 4C. Each data point is the mean angle of 33 estimations ( 3 trials $\times 11$ subjects). The best-fitting least squares function was $y=1.01 x-0.20\left(r^{2}=.998\right)$, with the $95 \% \mathrm{CI}$ around the slope being $0.97-1.05$. This suggests that correct estimations were made for visual plane angle.

\section{EXPERIMENT 4}

In Experiment 4, we also obtained judgments of body tilt under the $0^{\circ}$ and the $72^{\circ}$ adaptation. However, instead of the method of absolute estimation, we used the method of absolute production, which is the inverse operation of absolute estimation. For each trial, the experimenter told the subject the tilt angle and then required him or her to adjust the body orientation to produce it.

The method of absolute production had two merits in this experiment. First, absolute production was a valuable method of examining the validity of a function obtained by absolute estimation. If the absolute estimation is a valid method of constructing a scale for body tilt, we should also obtain an absolute production function that is similar to the absolute estimation function. Second, an absolute production function, together with an absolute estimation function, is useful to construct an unbiased function of apparent tilt. It has been well documented that, although the magnitude estimation function and the magnitude production function are skewed by systematic errors inherent in the scaling procedure, the errors are eliminated by averaging the two functions (e.g., Gescheider, 1985; Hellman \& Zwislocki, 1963; Stevens, 1958; Stevens \& Guirao, 1962). Following this precedent, the absolute estimation and production functions were averaged.

\section{Method}

Subjects. The subjects were 11 ( 2 males and 9 females) paid undergraduates; none of them had any known deficits in motor or vestibular functions.

Procedure. The subject was seated, blindfolded, in the same apparatus as that used in Experiments 1-3. The subject adjusted his or her own body to the tilt designated by the experimenter. In each trial, the chair was rotated $\mathrm{CW}$ or $\mathrm{CCW}$ at the rate of $1.20 \mathrm{rpm}$ and was stopped by the experimenter immediately upon being signaled by the subject. The experimenter then recorded the tilt angle of the chair in degrees.

The tilts to be adjusted were told to the subject in terms of clock minutes, rather than degrees of arc, because the unit minute was thought to be more familiar than the unit degree of arc. For the $0^{\circ}$ adaptation, the designated tilts were $0,5,10,15,20,40,45,50$, and $55 \mathrm{~min}$, which were equivalent to $0^{\circ},+30^{\circ},+60^{\circ},+90^{\circ},+120^{\circ}$, $-120^{\circ},-90^{\circ},-60^{\circ}$, and $-30^{\circ}$ of arc. The trials were composed of four blocks, each containing the nine different tilts. The order of

Table 5

Slope, Intercept, Coefficient of Determination $\left(r^{2}\right)$, and $95 \%$ Confidence Interval (CI) Around the Slope of the Linear Function Fitted to the Mean Estimations in Each Block Under the $72^{\circ}$ Adaptation

\begin{tabular}{ccccc}
\hline Block & Slope & Intercept & $r^{2}$ & CI \\
\hline 1 & 1.28 & -10.86 & .987 & $1.17-1.39$ \\
2 & 1.25 & -14.02 & .991 & $1.16-1.34$ \\
3 & 1.17 & -9.39 & .997 & $1.12-1.22$ \\
\hline
\end{tabular}

Table 6

Slope, Intercept, and Coefficient of Determination $\left(r^{2}\right)$ of the Linear Functions Fitted to the Mean Estimations for Each of the Two Ranges $\left(-18^{\circ}<x<-36^{\circ}\right.$, and $\left.x>54^{\circ}\right)$ as a Function of Block Under the $72^{\circ}$ Adaptation

\begin{tabular}{cccccccc}
\hline & \multicolumn{3}{c}{ Small } & & \multicolumn{3}{c}{ Large } \\
\cline { 2 - 3 } \cline { 6 - 8 } Block & Slope & Intercept & $r^{2}$ & & Slope & Intercept & $r^{2}$ \\
\hline 1 & 1.07 & -9.79 & .999 & & 1.31 & -13.92 & .958 \\
2 & 1.21 & -12.50 & .999 & & 1.31 & -21.03 & .972 \\
3 & 1.38 & -10.31 & .993 & & 1.17 & -10.42 & .996 \\
Overall & 1.21 & -10.60 & .998 & & 1.26 & -15.13 & .985 \\
\hline
\end{tabular}




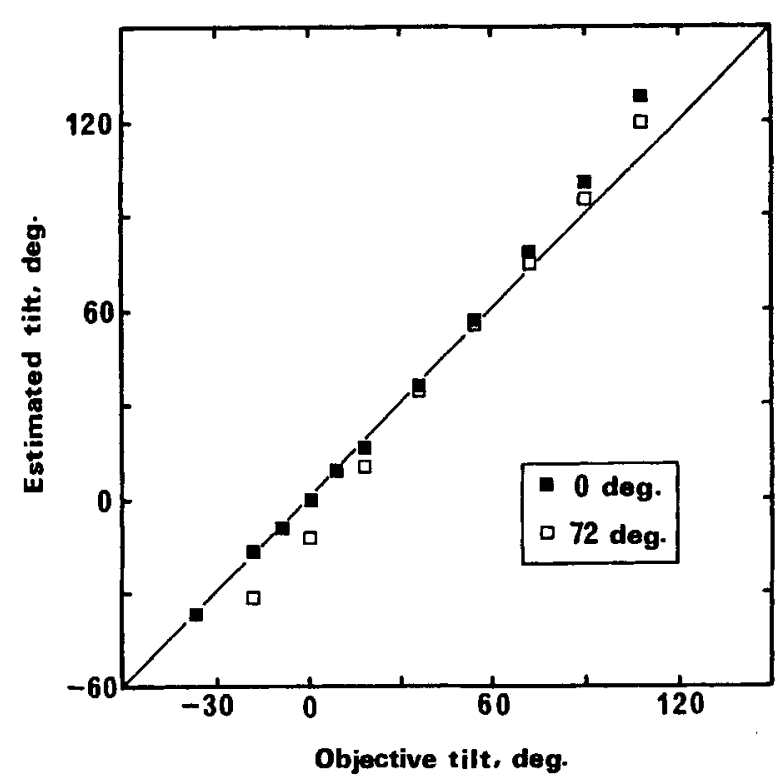

Figure 9. Comparison of the absolute estimations obtained under the $0^{\circ}$ adaptation (Experiment 1) and the $72^{\circ}$ adaptation (Experiment 3). The diagonal line represents the perfect estimation.

the designated angles in each block was randomly determined, with the restriction that they were an alternation of left and right tilts of the gravitational vertical.

The main part of the instructions to the subjects was:

I am telling you a series of tilt angles in clock minutes. These numbers stand for your body tilt to be adjusted. Imagine your body to be a minute hand of a large clock, and incline your body laterally so as to fit to the tilt angle. For example, when I tell you " 10 minutes," you have to bring your body to " 20 'clock," or to a $60^{\circ} \mathrm{CW}$ tilt from the gravitational ver- tical. Please say "Stop" when you think the orientation of your body agrees with the designated tilt angle.

After completing the adjustments under the $0^{\circ}$ adaptation, the subject was tilted by $72^{\circ} \mathrm{CW}$ for a period of $10 \mathrm{~min}$. The subject was thereafter asked to adjust the body orientation to the position designated by the experimenter. The designated numbers were 0,4 , $9,12,15,20,24,29$, and $55 \mathrm{~min}$, which were equivalent to $0^{\circ}, 24^{\circ}$, $54^{\circ}, 72^{\circ}, 90^{\circ}, 120^{\circ}, 144^{\circ}, 174^{\circ}$, and $-30^{\circ}$. The trials were composed of four blocks, each containing the nine different designated angles. The order of trials in each block was randomly determined, with the restriction that the designated angles were composed of an alternation of left and right of the adapting tilt.

Finally, the subject produced visual plane angles by adjusting a separation between two thin iron rods (each $9.8 \mathrm{~cm}$ long $\times 0.8 \mathrm{~mm}$ in diameter) that were fixed on a white disk ( $18 \mathrm{~cm}$ in diameter), like the hands of a clock. One rod was maintained stationary, and the other could be rotated around the center of the disk. The subject had the disk in his or her hand, and he or she maintained the stationary rod vertical and attempted to set the variable rod up to angles requested by the experimenter. The angles to be adjusted were 35,40 , $45,50,55,5,10,15,20$, and $25 \mathrm{~min}$, or $-150^{\circ},-120^{\circ},-90^{\circ},-60^{\circ}$, $-30^{\circ},+30^{\circ},+60^{\circ},+90^{\circ},+120^{\circ}$, and $+150^{\circ}$ of arc. The trials were composed of two blocks, each block containing 10 different plane angles. The adjusted angles were measured to an accuracy of $1^{\circ}$ by reading the scale on the rear of the disk.

\section{Results and Discussion}

The left and right panels of Figure 10 show the mean productions taken over the subjects for the $0^{\circ}$ and the $72^{\circ}$ adaptation, respectively. In each adaptation, the ordinate represents the angle designated by the experimenter, and the abscissa represents the mean tilt adjusted to the designated angle. For the $0^{\circ}$ adaptation, the main effect of angle was significant $[F(8,30)=453.04, p<.001]$, and the interaction of angle with block was significant $[F(24$, $240)=6.94, p<.01]$. The main effect of block was not significant. For the $72^{\circ}$ adaptation, the main effects of
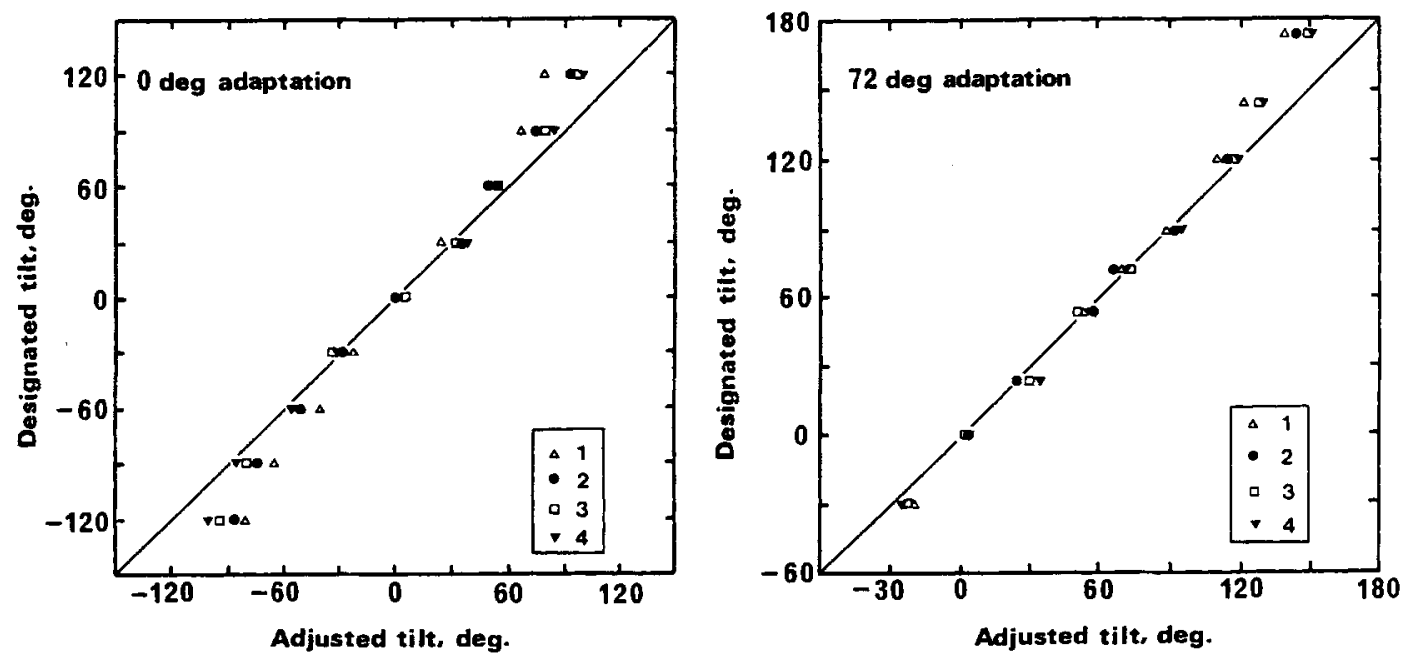

Figure 10. Mean body tilt (in degrees) adjusted to the angle designated under the $0^{\circ}$ adaptation (left) and the $72^{\circ}$ adaptation (right). To compare these results with the results of absolute estimation, the ordinate represents the designated angle, and the abscissa represents the mean adjusted tilt (in degrees). The diagonal line represents the perfect estimation. 
angle $[F(8,30)=363.55, p<.001]$ and block $[F(3,30)=$ $4.84, p<.01]$ were significant, and the interaction of angle with block was significant $[F(24,240)=1.96, p<.01]$.

The outcome that the main effect of block was significant under the $72^{\circ}$ adaptation but was not under the $0^{\circ}$ adaptation may have been due to the difference in range of designated angles. Under the $0^{\circ}$ adaptation, the tilts were equally designated to the left and right of the gravitational vertical, but, under the $72^{\circ}$ adaptation, they were mostly designated to the right of the gravitational vertical.

The significant interaction of angle with block in each adaptation suggests different slopes of the four functions. Table 7 shows the least squares line that was fitted to the designated tilt as a function of mean adjusted tilt in each block under the $0^{\circ}$ adaptation. Table 8 shows the least squares lines fitted to the same data separately for the small tilts, large CW tilts, and large CCW tilts. The slope across the entire set of data decreased from 1.41 to 1.12 as the block progressed, and it was significantly larger than unity even at the final fourth block. For the partitioned data, the slope was shallow for the small tilts (0.99) and was steep for the large tilts (mean slope 1.43 for the CW and $(\mathrm{CW}$ ), and the intercept was approximately 0 for the small tilts but was remote from 0 for the large tilts.

Similarly, Tables 9 and 10 show the least squares lines fitted to the entire and partitioned sets of data under the $72^{\circ}$ adaptation, respectively. The slope across the entire set of data decreased from 1.23 to 1.13 as the block progressed, and it was significantly larger than unity even at the final fourth block. For the partitioned data, the slope was shallow for the small tilts (1.01) and was steep for the large tilts (1.29), and the intercepts were negative for both small and large tilts.

Figure 11 helps us to compare the absolute productions between the $0^{\circ}$ and the $72^{\circ}$ adaptation. Clearly, the adjustments under the $72^{\circ}$ adaptation were larger than those under the $0^{\circ}$ adaptation, and the discrepancy of adjustments between the two adaptations was greater for the test tilts that were farther away from the adapting tilt. In particular, this tendency was noticeable for the test tilts that were larger than the adapting tilt.

Figure 4D shows the designated angle as a function of mean visual orientation adjusted in the frontal plane. Each data point is the mean angle of 22 productions ( 2 trials $\times 11$ subjects). The best-fitting least squares func-
Table 7

Slope, Intercept, Coefficient of Determination $\left(\boldsymbol{r}^{2}\right)$, and $95 \%$ Confidence Interval (CI) Around the Slope of the Linear Function Fitted to the Mean Productions in Each Block Under the $0^{\circ}$ Adaptation

\begin{tabular}{ccccc}
\hline Block & Slope & Intercept & $r^{2}$ & CI \\
\hline 1 & 1.41 & -1.69 & .996 & $1.33-1.50$ \\
2 & 1.26 & -1.72 & .995 & $1.17-1.34$ \\
3 & 1.16 & -0.51 & .994 & $1.08-1.24$ \\
4 & 1.12 & -0.75 & .994 & $1.04-1.20$ \\
\hline
\end{tabular}

tion was $y=1.00 x-0.03\left(r^{2}=.999\right)$, with the $95 \% \mathrm{CI}$ around the slope being $0.98-1.02$. Clearly, the absolute productions for plane angle were very exact.

\section{GENERAL DISCUSSION}

\section{Unbiased Scale}

In Experiments 1, 3, and 4, in which the velocity of the chair was $1.20 \mathrm{rpm}$, we obtained the least squares functions for combinations of range (small and large), method (estimation and production), and adaptation $\left(0^{\circ}\right.$ and $\left.72^{\circ}\right)$. By averaging the estimation function and the production function, we obtained four unbiased functions, one for each combination of range and adaptation. ${ }^{3}$ Figure 12 shows the unbiased functions, together with the least squares functions, in Experiments 1, 3, and 4. For the $0^{\circ}$ adaptation, the unbiased function was

$$
y= \begin{cases}0.98 x-0.85 & \text { for }-30^{\circ}<x<45^{\circ} \\ 1.40 x-17.46 & \text { for } x \geq 45^{\circ}\end{cases}
$$

For the $72^{\circ}$ adaptation, the unbiased function was

$$
y= \begin{cases}1.11 x-7.74 & \text { for }-30^{\circ}<x<45^{\circ} \\ 1.28 x-17.96 & \text { for } x \geq 45^{\circ}\end{cases}
$$

Equations 1 and 2 indicate that the slope for the small tilts was steeper under the $72^{\circ}$ adaptation than under the $0^{\circ}$ adaptation, whereas the slope for the large tilts was shallower under the $72^{\circ}$ adaptation than under the $0^{\circ}$ adaptation. Note also that, for the small tilts, the difference in slope between the $0^{\circ}$ and the $72^{\circ}$ adaptation was 0.13 , whereas for the large tilts, the difference in slope between the two adaptations was 0.12 . Thus, it is clear that the off-adaptation took place over the test tilts used, and the

Table 8

Slope, Intercept, and Coefficient of Determination $\left(\boldsymbol{r}^{2}\right)$ of the Linear Functions Fitted to the Mean Productions for Each of the Three Ranges $\left(x<-54^{\circ}, 36^{\circ}<x<36^{\circ}\right.$, and $\left.x>54^{\circ}\right)$ as a Function of

\begin{tabular}{|c|c|c|c|c|c|c|c|c|c|}
\hline \multirow[b]{2}{*}{ Block } & \multicolumn{3}{|c|}{ Small } & \multicolumn{3}{|c|}{ Large $(\mathrm{CCW})$} & \multicolumn{3}{|c|}{ Large $(\mathrm{CW})$} \\
\hline & Slope & Intercept & $r^{2}$ & Slope & Intercept & $r^{2}$ & Slope & Intercept & $r^{2}$ \\
\hline 1 & 1.26 & -1.42 & .995 & 1.45 & 0.62 & .985 & 1.93 & -35.31 & .981 \\
\hline 2 & 0.98 & & .998 & 1.54 & 17. & .968 & 1.39 & -10.95 & .992 \\
\hline 3 & 0.89 & -1.08 & .994 & 1.35 & 14.08 & .987 & 1.41 & -18.37 & .975 \\
\hline 4 & 0.89 & -2.09 & .995 & 1.21 & 6.68 & .955 & 1.28 & -12.10 & .972 \\
\hline Overall & 0.99 & -1.51 & .999 & 1.38 & 9.64 & .975 & 1.47 & -17.95 & .981 \\
\hline
\end{tabular}
Block Under the $0^{\circ}$ Adaptation 
Table 9

Slope, Intercept, Coefficient of Determination $\left(r^{2}\right)$, and $95 \%$ Confidence Interval (CI) Around the Slope of the Linear Function Fitted to the Mean Productions in Each Block Under the $72^{\circ}$ Adaptation

\begin{tabular}{ccccc}
\hline Block & Slope & Intercept & $r^{2}$ & CI \\
\hline 1 & 1.23 & -9.51 & .988 & $1.10-1.35$ \\
2 & 1.15 & -4.59 & .990 & $1.04-1.25$ \\
3 & 1.13 & -6.46 & .990 & $1.04-1.24$ \\
4 & 1.13 & -8.05 & .990 & $1.03-1.24$ \\
\hline
\end{tabular}

Table 10

Slope, Intercept, and Coefficient of Determination $\left(r^{2}\right)$ of the Linear Functions Fitted to the Mean Productions for Each of the Two Ranges $\left(-18^{\circ}<x<-36^{\circ}\right.$, and $\left.x>54^{\circ}\right)$ as a Function of Block Under the $72^{\circ}$ Adaptation

\begin{tabular}{cccccccc}
\hline & \multicolumn{3}{c}{ Small } & & \multicolumn{3}{c}{ Large } \\
\cline { 2 - 3 } \cline { 6 - 8 } Block & Slope & Intercept & $r^{2}$ & & Slope & Intercept & $r^{2}$ \\
\hline 1 & 1.02 & -6.42 & .981 & & 1.40 & -27.50 & .983 \\
2 & 1.11 & -2.54 & .999 & & 1.25 & -15.86 & .972 \\
3 & 1.01 & -4.58 & .992 & & 1.23 & -17.17 & .976 \\
4 & 0.91 & -5.68 & .991 & & 1.26 & -22.43 & .985 \\
Overall & 1.01 & -4.88 & .993 & & 1.29 & -20.79 & .981 \\
\hline
\end{tabular}

degrees of adaptation for the small and large tilts were approximately equal in magnitude.

With Equations 1 and 2, we obtained the body tilt $x$ at which the subjects perceived themselves as being upright $\left(y=0^{\circ}\right)$. This tilt was $0.87^{\circ}$ for the $0^{\circ}$ adaptation and $6.97^{\circ}$ for the $72^{\circ}$ adaptation. In other words, the gravitational vertical was perceived as being almost upright under the $0^{\circ}$ adaptation, whereas the tilt of $6.97^{\circ}$ to the direction of the adapting stimulus was perceived as being upright under the $72^{\circ}$ adaptation. This result supported the classic studies based on the matching method (Clegg, 1954; Clegg \& Dunfield, 1954a, 1954b; Fleishman, 1953; Howard \& Templeton, 1966; Mann \& Passey, 1951; Pearson \& Hauty, 1959; Solley, 1956), which indicated that, after adapting to tilted position, the subject inclined his or her body by $0.5^{\circ}-6.0^{\circ}$ to the direction of the adapting stimulus in order to perceive the body as being upright.

Also interesting is the body tilt $x$ at which the subjects perceived themselves as being horizontal. From Equations 1 and 2, the value of $x$ for the $y$ of $90^{\circ}$ was $76.8^{\circ}$ for the $0^{\circ}$ adaptation and $84.3^{\circ}$ for the $72^{\circ}$ adaptation. These values were much smaller than the true value. In addition, the fact that the difference between the two values was $7.5^{\circ}$ suggests that, by prolonged exposure to the $72^{\circ}$ body tilt, the apparent horizontal rotated $\mathrm{CW}$ by much the same degree as the apparent vertical.

\section{Receptors}

Since Equations 1 and 2 suggested that a single process underlies the perception of body tilt, the next issue was to explore the proprioceptors contributing to the process. There are some possible proprioceptors to consider. The first is the cutaneous. The distribution of pressure on skin seems to be available for the perception of body tilt. The distribution of pressure indeed varied with changes in body tilt in this study. When the subject was seated upright in a chair, pressure occurred mainly at his or her posterior and thighs; when the chair was tilted by $90^{\circ}$, the center of the pressure distribution shifted to his or her lateral side. If the chair was tilted by an angle between the two extremes, deep pressure occurred at both the posterior and the side. It appears to us that distribution of pressure on the skin by activity of many cutaneous receptors, rather than absolute location and magnitude of a sensation arising from isolated stimulation to single receptors, is the critical determiner of the perception of body tilt.

Some of the mechanoreceptors, such as Merkel cells, Ruffini receptors, Meissner corpuscles, Pacinian corpuscles, and free nerve endings, seem to convey information of the pressure distribution in skin to the central nervous system. Although these receptors are classified into four categories on the basis of the speed of adaptation and the size of receptive field (Cholewiak \& Collins, 1991), the slow adapting receptors, such as Merkel cells and Ruffini receptors, rather than rapid adapting receptors, such as Meissner and Pacinian corpuscles, have the advantage of detecting the static position of body or limbs (F. J. Clark $\&$ Horch, 1986). Because these cutaneous proprioceptors distribute over the wide area of cutaneous tissue, they appear to provide the central nervous system with spatially and temporally coded information associated with changes in distributions of pressure that result from change in body tilt. ${ }^{4}$

There are several well-known demonstrations of the importance of cutaneous proprioceptors in human spa-

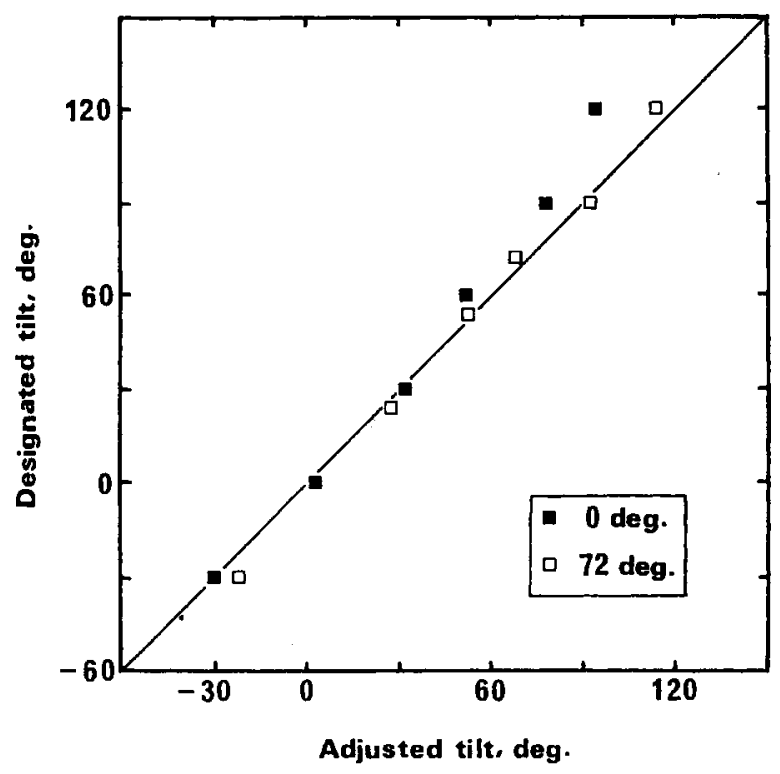

Figure 11. Comparison of the absolute productions obtained under the $0^{\circ}$ adaptation (left) and the $72^{\circ}$ adaptation (right). The diagonal line represents the perfect estimation. 


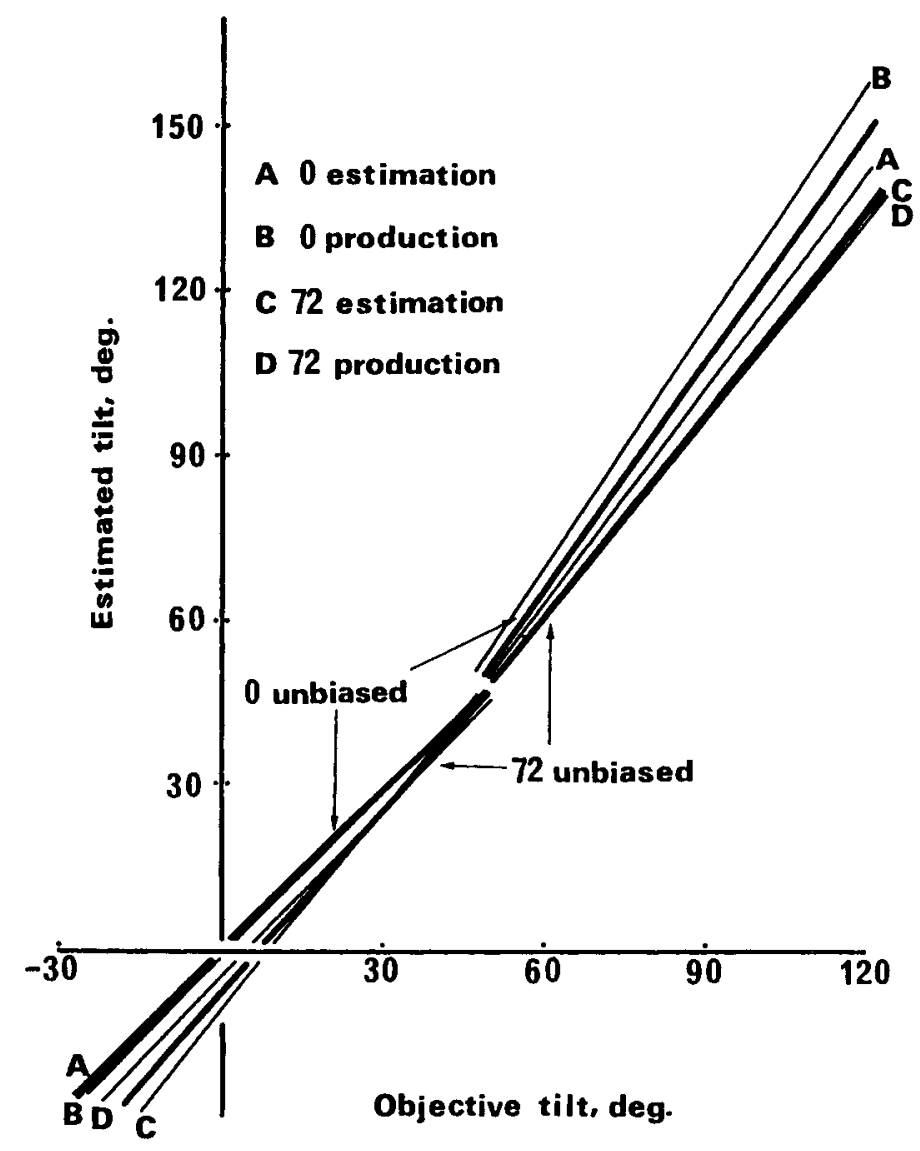

Figure 12. Unbiased functions obtained under the $0^{\circ}$ and the $72^{\circ}$ adaptations (thick lines), together with absolute estimation and production functions under the $0^{\circ}$ and the $72^{\circ}$ adaptations (thin lines).

tial orientation. First, an experienced pilot of an aircraft lost all ability to orient himself in acrobatic flight when his posterior was anesthetized with novocaine. This has been interpreted as a direct test of the adage, "Experienced pilots can fly by the seats of their pants" (Cohen, 1981). Second, in free-fall phases of parabolic flight where zero gravity or microgravity was attained (Lackner \& Graybiel, 1979), a blindfolded subject, who was rotated at constant velocity about the longitudinal body axis, lost the sense of body motion and orientation, but, when touch and pressure stimulation was applied to the body skin, a sense of body orientation was established immediately. Lackner (1992) also reported that when subjects were strapped in position in aircraft seats under the zero-gravity phases of parabolic flight, most subjects felt upside down as if they were hanging from their lap belts. He considered this sense of self-inversion to be triggered by the tactile cues provided by the restraint belt. Third, when subjects were required to indicate direction of the gravitational vertical under the condition of total body immersion in water, it was found that (1) their responses were exceedingly more variable than responses obtained under terrestrial conditions (Adolfson \& Berghage, 1974;
Nelson, 1968; Ross, 1972) and (2) the mean pointing error was about $7^{\circ}$ for the upright blindfolded divers who were strapped to the chair or tables in a pool and $16.8^{\circ}$ for the upright blindfolded free swimmers in the sea (Ross, 1990). Since the otolith organs in the inner ear continue to respond to gravity even for subjects under water, the pointing errors are due to the change in cutaneous information to the subjects under water. Finally, anesthesia of the skin covering the tongue or the lips makes speech difficult, and we tend to bite the tongue in such a situation (F. J. Clark \& Horch, 1986).

Muscular tension may contribute to the judgments of body tilt. When the chair in which the subject was placed was upright, there was muscular tension that was symmetric with respect to the gravitational vertical; however, when the chair was largely tilted, the subject's limbs (in particular, the legs) were likely to hang down from the chair, so that the subject had to hold the limbs parallel to the trunk against the gravity. This forced the subject to be at asymmetric muscular tension that differs from the normal tension.

The otolith organs in the vestibular system may be eliminated from the possible sources in the perception of body 
tilt. First, since the otolith organs are effective only for small tilts from the gravitational vertical (Graybiel \& Patterson, 1955; Quix, 1925; Schöne, 1964; Schöne \& Mortag, 1968; Schöne \& Wade, 1971; Udo de Haes, 1970), it is difficult to explain the extended postural aftereffects as obtained in this study. Second, during 3-min exposure to centrifugal force, labyrinthine-defective subjects differed from normals in oculogravic illusion (B. Clark \& Graybiel, 1965; Graybiel \& B. Clark, 1965), but, after 20-min exposure to the force, the labyrinthine-defective subjects did show the same amount of illusion as the normals did (B. Clark \& Graybiel, 1966). Third, settings of postural vertical (B. Clark \& Graybiel, 1963) and visual horizontal (B. Clark \& Graybiel, 1967) did not differ between the labyrinthine-defective and the normal subjects. Last, a subject lacking somatosensory function below the neck did not show the A effect, in contrast with normal subjects who exhibited it (Yardley, 1990). These findings suggest an importance of somatosensory function, rather than the otolith organs, on the visual orientation.

Joint receptors, which include Ruffini receptors and Golgi-Mazzoni corpuscles, did not seem to greatly contribute to the perception of body tilt. These receptors are found in tissue at or near joints, and they usually respond to sudden movements of their adjacent joints or to pressures resulting from the displacement of joints. Several studies have indeed indicated effectiveness of joint receptors on postural aftereffects and visual orientation when the joints moved naturally at the shoulder (Craske \& Crawshaw, 1974) and at the neck (Howard \& Anstis, 1974). However, since in this study, the large joints, such as the neck, the shoulders, and the waist, were steadily held in usual normal connection with the trunk, there were no movements and displacements of the large joints. This suggests that there was not sufficient proprioceptive information from joint receptors. Also, in a review of physiological evidence (F. J. Clark \& Horch, 1986), it was concluded that joint receptors do not encode position of the joint except for extreme positions of the joint.

In summary, we suggest that the judgments of body tilt were subserved by a single sensory process. A major ground for this suggestion was that postural aftereffect, which was formed by adapting the body to a certain fixed tilt, extended to either side of the adapting tilt, and was strengthened for the test body tilts remote from the adapting tilt (i.e., the off-adaptation). We also suggest that the process of body tilt perception was probably influenced by the cutaneous and muscular proprioceptors, not by the otolith and joint proprioceptors. Future research should focus on the issue of how these effective proprioceptors are combined in a process of determining apparent body tilt. We believe that postural adaptation can provide a useful tool for this purpose.

\section{REFERENCES}

Adolfson, J., \& Berghage, T. (1974). Perception and performance under water. New York: Wiley.

Asch, S. E., \& WITKIN, H. A. (1948a). Studies in space orientation:
I. Perception of the upright with displaced visual fields. Journal of Experimental Psychology, 38, 325-337.

AsCH, S. E., \& WITKIN, H. A. (1948b). Studies in space orientation: II. Perception of the upright with displaced visual fields and with body tilted. Journal of Experimental Psychology, 38, 455-477.

BAUERMEISTER, M. (1964). Effect of body tilt on apparent verticality, apparent body position, and their relation. Journal of Experimental Psychology, 67, 142-147.

BAUERMEISTER, M., WERNER, H., \& WAPNER, S. (1964). The effect of body tilt on tactual-kinesthetic perception of verticality. American Journal of Psychology, 77, 451-456.

Blakemore, C., \& Campbell, F. W. (1969). On the existence of neurons in the human visual system selectively sensitive to the orientation and size of retinal images. Journal of Physiology, 203, 237-261.

Cholewiak, R., \& Collins, A. (1991). Sensory and physiological bases of touch. In M. A. Heller \& W. Schiff (Eds.), The psychology of touch (pp. 23-62). Hillsdale, NJ: Erlbaum.

Clark, B., \& Graybiel, A. (1963). Perception of postural vertical in normals and subjects with labyrinthine defects. Journal of Experimental Psychology, 65, 490-494.

Clark, B., \& Graybiel, A. (1965). Perception of the postural vertical following prolonged bodily tilt in normals and subjects with labyrinthine defects. Acta Oto-Laryngologica, 58, 143-148.

Clark, B., \& Graybiel, A. (1966). Perception of the visual horizontal in normal and labyrinthine defective observers during prolonged rotation. American Journal of Psychology, 79, 608-612.

Clark, B., \& Graybiel, A. (1967). Egocentric localization of the visual horizontal in normal and labirinthine-defective observers as a function of head and body tilt. Perception \& Psychophysics, 2, 609611

Clark, F. J., \& Horch, K. W. (1986). Kinesthesis. In K. R. Boff, L. Kaufman, \& J. P. Thomas (Eds.), Handbook of perception and human performance. Vol. 1 : Sensory processes and perception (pp. 13.113.63). New York: Wiley.

CLEGG, W. C. (1954). Non-visual perception of the postural vertical: III. Diagonal planes. Canadian Journal of Psychology, 8, 209-213.

ClegG, W. C., \& Dunfield, N. M. (1954a). Non-visual perception of the postural vertical: I. Sagittal planes. Canadian Journal of Psychology, 8, 1-8.

ClegG, W. C., \& Dunfield, N. M. (1954b). Non-visual perception of the postural vertical: II. Lateral planes. Canadian Journal of Psychology, 8, 80-86.

COHEN, M. M. (1981). Visual-proprioceptive interactions. In R. D. Walk \& H. L. Pick, Jr. (Eds.), Intersensory perception and sensory integration (pp. 175-215). New York: Plenum.

Cohen, M. M., Ebenholtz, S. M., \& Linder, B. J. (1995). Effects of optical pitch on oculomotor control and the perception of target elevation. Perception \& Psychophysics, 57, 433-440.

Cohen, M. M., \& Larson, C. A. (1974). Human spatial orientation in the pitch dimensinn. Perception \& Psychophysics, 16, 508-512.

Craske, B., \& Crawshaw, M. (1974). Differential errors of kinesthesis produced by previous limb positions. Journal of Motor Behavior, 6, 273-278.

DicK, M., \& Hochstein, S. (1989). Visual orientation estimation. Perception \& Psychophysics, 46, 227-234.

EBENhOLTZ, S. M. (1970). Perception of the vertical with body tilt in the median plane. Journal of Experimental Psychology, 83, 1-6.

EBENHOLTZ, S. M. (1977). The constancies in object orientation: An algorithm processing approach. In W. Epstein (Ed.), Stability and constancy in visual perception: Mechanisms and processes (pp. 71-89). New York: Wiley.

Ebenholtz, S. M., \& Benzschawel, T. L. (1977). The rod and frame effect and induced head tilt as a function of observation distance. Perception \& Psychophysics, 22, 491-496.

EBEnholtz, S. M., \& SHEBILSKe, W. (1973). Instructions and the A and $\mathrm{E}$ effects in judgments of the vertical. American Journal of Psychology, 86, 601-612.

Fleishman, E. A. (1953). Perception of body position in the absence of visual cues. Journal of Experimental Psychology, 46, 261-270.

FusitA, A. (1956). An effect of apparatus exercise on perception of upright. Research Journal of Physical Education, 2, 94-100. 
Gescheider, G. A. (1985). Psychophysics: Method, theory, and application. Hillsdale, NJ: Erlbaum.

Graybiel, A., \& Clark, B. (1965). Validity of the oculogravic illusion as a specific indication of otolith function. Aerospace Medicine, 36, 1173-1181.

Graybiel, A., \& Patterson, J. L. (1955). Thresholds of stimulation of the otholith organs as indicated by the oculogravic illusion. Journal of Applied Physiology, 7, 666-670.

GREENSPAN, J. D., \& Bolanowski, S. J. (1996). The psychophysics of tactile perception and its peripheral physiological basis. In L. Kruger (Ed.), Pain and touch (pp. 25-103). San Diego, CA: Academic Press.

HellmaN, R. P., \& ZWISLOCKI, J. J. (1963). Monaural loudness function of a 1000-cps tone and internal summation. Journal of the Acoustical Society of America, 35, 856-865.

HowARD, I. P. (1982). Human visual orientation. New York: Wiley.

HoWARD, I. P., \& ANSTIS, T. (1974). Muscular and joint-receptor components in postural resistance. Journal of Experimental Psychology, 103, 167-170.

Howard, I. P., \& TEMPLETON, W. B. (1966). Human spatial orientation. London: Wiley.

JENKIN, W. L. (1951). Somesthesis. In S. S. Stevens (Ed.), Handbook of experimental psychology (pp. 1172-1190). New York: Wiley.

Kenshalo, D. R. (1978). Biophysics and psychophysics of feeling. In E. C. Carterette \& M. P. Friedman (Eds.), Handbook of perception: Vol. VIB. Feeling and hurting (pp. 29-74). New York: Academic Press.

KöHLER, W., \& WALLACH, H. (1944). Figural after-effects: An investigation of visual processes. Proceedings of the American Philosophical Association, 88, 269-375.

LACKNER, J. R. (1992). Spatial orientation in weightless environments. Perception, 21, 803-812.

LACKNER, J. R., \& GraYbIEL, A. (1979). Parabolic flight: Loss of sense of orientation. Science, 206, 1105-1108.

MANN, C. W. (1952). Visual factors in the perception of verticality. Journal of Experimental Psychology, 44, 460-464.

MANN, C. W., \& PAsSEY, G. E. (1951). The perception of the vertical: $\mathrm{V}$. Adjustment to the postural vertical as a function of the magnitude of postural tilt and duration of exposure. Journal of Experimental Psychology, 41, 108-113.

Matin, L., \& Fox, C. R. (1989). Visually perceived eye level and perceived elevation of objects: Linearly additive influences from visual field pitch and gravity. Vision Research, 29, 315-324.

Matin, L., \& LI, W. (1994). The influence of a stationary single line in darkness on the visual perception of eye level. Vision Research, 34, 311-330.

MILLER, J. W., \& HALL, R. J. (1963). Accuracy of orientation and positioning in homogeneous visual fields. Aerospace Medicine, 34, 337-341.

Nelson, J. G. (1968). Effect of water immersion and body position upon perception of the gravitational vertical. Aerospace Medicine, 39, 806-811.

NemiRE, K., \& COHEN, M. M. (1993). Visual and somesthetic influences on postural orientation in the median plane. Perception \& Psychophysics, 53, 106-116.

PASSEY, G. E. (1950). The perception of the vertical: IV. Adjustment to the vertical with normal and tilted visual frames of reference. Journal of Experimental Psychology, 40, 738-745.

Pearson, R. G., \& HaUty, G. T. (1959). Adaptive processes determining proprioceptive perception of verticality. Journal of Experimental Psychology, 57, 367-371.

QuIX, F. H. (1925). The function of the vestibular organ and the clinical examination of the otolithic apparatus. Journal of Laryngology \& Otology, 40, 425-443 and 493-511.

RoBinson, J. O. (1972). The psychology of visual illusion. London: Hutchinson University Library.

Ross, H. E. (1972). Behaviour and perception in strange environments. London: Allen \& Unwin.

Ross, H. E. (1990). Orientation and movement in divers. In R. Warren \& A. H. Wertheim (Eds.), Perception \& control of self-motion (pp. 463486). Hillsdale, $\mathrm{NJ}$ : Erlbaum.

SCHÖNE, H. (1964). On the role of gravity in human spatial orientation. Aerospace Medicine, 35, 764-772.
SCHöNE, H., \& LeCHNER-STEINLEITNER, S. (1978). The effect of preceding tilt on the perceived vertical: Hysteresis in perception of the vertical. Acta Oto-Laryngologica, 85, 68-73.

SchöNE, H., \& MoRTAG, H.-G. (1968). Variation of the subjective vertical on the parallel swing at different body positions. Psychologische Forschung, 32, 124-134.

SchöNe, H., \& UdO DE HAEs, H. (1968). Perception of gravity-vertical as a function of head and trunk position. Zeitschrift für vergleichende Physiologie, 60, 440-444.

SCHÖNE, H., \& WADE, N. J. (1971). The influence of force magnitude on the perception of body position: II. Effect of body posture. British Journal of Psychology, 62, 347-352.

ShebilsKe, W. L., \& Fogelgren, L. (1977). Eye-position aftereffects of backward head tilt manifested by illusory visual direction. Perception \& Psychophysics, 21, 77-82.

SheBILSKE, W. L., \& KARMIOHL, C. M. (1978). Illusory visual direction during and after backward head tilts. Perception \& Psychophysics, 24, 543-545.

Sigman, E., Goodenough, D. R., \& Flannagan, M. (1979). Instructions, illusory self-tilt and the rod-and-frame test. Quarterly Journal of Experimental Psychology, 31, 155-165.

SOLLEY, C. M. (1956). Reduction of error with practice in perception of the postural vertical. Journal of Experimental Psychology, 52, 329-333.

Stevens, S. S. (1958). Problems and methods of psychophysics. Psychological Bulletin, 55, 177-196.

Stevens, S. S. (1975). Psychophysics. New York: Wiley.

STEVENS, S. S., \& GuIraO, M. (1962). Loudness, reciprocality, and partition scales. Journal of the Acoustical Society of America, 34, 14661471.

StoffRegen, T. A., \& Riccio, G. E. (1988). An ecological theory of orientation and the vestibular system. Psychological Review, 95, 3-14.

STOPER, A. E., \& CohEn, M. M. (1986). Judgments of eye level in light and in darkness. Perception \& Psychophysics, 40, 311-316.

STOPER, A. E., \& COHEN, M. M. (1989). Effect of structured visual environments on apparent eye level. Perception \& Psychophysics, 46, 469-475.

TSCHERMAK-SEYSENEGG, A. vON (1952). Introduction to physiological optics (P. Boeder, Trans.). Springfield, IL: Charles C. Thomas (Original work published 1942)

Udo DE HAES, H. A. (1970). Stability of apparent vertical and ocular countertorsion as a function of lateral tilt. Perception \& Psychophysics, $8,137-142$

WADE, N. J. (1968). Visual orientation during and after lateral head, body, and trunk tilt. Perception \& Psychophysics, 3, 215-219.

WADE, N. J. (1970). Effect of prolonged tilt on visual orientation. Quarterly Journal of Experimental Psychology, 22, 423-439.

WADE, N. J., \& DAY, R. H. (1968). Apparent head position as a basis for a visual aftereffect of prolonged head tilt. Perception $\&$ Psychophysics, 3, 324-326.

WITKIN, H. A. (1949). Perception of body position and of the position of the visual field. Psychological Monographs, 63(Whole No. 302).

YARDLEY, L. (1990). Contribution of somatosensory information to perception of the visual vertical with body tilt and rotating visual field. Perception \& Psychophysics, 48, 131-134.

\section{NOTES}

1. According to Howard (1982), we used the term tilt or roll when the body or head is tilted to gravity within a frontal plane of the subject, and we used the term slant or pitch when it is inclined within the median plane.

2. In this study, we used the term proprioception to represent the perception of location, orientation, and movement of the body or its parts. To avoid confusion by emphasizing subtle differences in terminology, we did not use the term kinesthesis, because proprioception is often interchangeable with kinesthesis (F. J. Clark \& Horch, 1986). We also did not use somesthesis (or feeling), because somesthesis has a somewhat vague meaning including cutaneous, kinesthetic, and internal sensations (Jenkin, 1951; Kenshalo, 1978).

3. Hellman and Zwislocki (1963), Gescheider (1985), and Stevens (1975) described a procedure for combining the power functions of 
magnitude estimation and magnitude production. For example, Stevens (1975) succinctly described, "When both estimation and production can be carried out in a balanced experimental design, we obtain two exponents, one too small and the other too large. It seems sensible therefore to average the two exponents. An appropriate average for that purpose is the geometric mean of the two exponents" (p. 32). Since, in this study, a linear function was fitted to the arithmetic means of estimations or productions, it seemed suitable to define the unbiased slope as the arithmetic, rather than geometric, mean of the two slopes.

4. We adapt to skin indentation that is steadily maintained for some time. From the studies in which a small limited area of skin was stimulated under very careful control, it has generally been found that the period necessary to achieve perfect adaptation (i.e., disappearance of "touch") increases with increasing depth of indentation, decreases with increasing contact area of the indenting stimulus, and varies inversely with the absolute sensitivity of body sites (e.g., Greenspan \& Bolanowski, 1996). However, it was difficult to predict how the cutaneous system adapted to $72^{\circ}$ body tilt in this study. When the subject was tilted in the rotating chair, the restraining structure of the chair pressed in a complicated way against the side of the body. That is, the distribution of the skin indentation by the tilted chair was not homogeneous, because both the body and the structure were not flat. For example, the pressure might be severe at shoulder and posterior but be mild at waist. Another factor that made it difficult to predict the adaptation of the cutaneous system was the large area of skin that was exposed to indentation. We do not know how the cutaneous system adapts to indentation of such a large area of skin.

(Manuscript received October 30, 1995; revision accepted for publication February 27, 1997.) 